Article

\title{
Competencies and Pedagogies for Sustainability Education: A Roadmap for Sustainability Studies Program Development in Colleges and Universities
}

\section{Tina Lynn Evans}

Colorado Mountain College, Glenwood Springs, CO 81601, USA; tevans@coloradomtn.edu; Tel.: +1-970-870-4517

Received: 19 July 2019; Accepted: 1 October 2019; Published: 7 October 2019

\begin{abstract}
Sustainability studies educators in colleges and universities must identify and teach the knowledge, skills, and abilities their graduates will most need to advance sustainability while confronting perhaps the most serious, sweeping, and integrated set of challenges humanity has ever known. Using a rigorous grounded theory and hermeneutics based analysis/synthesis of the relevant literature, this study articulates and describes in depth a set of five competencies for the sustainability field and suggests potentially effective pedagogies for teaching them. Findings in the areas of both competencies and pedagogies for sustainability education imply the benefits of integrative, active, collaborative, and applied approaches to curriculum development and teaching-approaches that directly involve students in learning and practicing transdisciplinary engagement in service to sustainability. The Bachelor of Arts in Sustainability Studies program at Colorado Mountain College serves as an example of how the articulated competency framework is being applied to evaluate and enhance curriculum and learning outcomes. The competency framework and pedagogical recommendations offered may also serve as roadmaps for educators at other institutions who prepare graduates to address the pressing challenges of sustainability evident in communities, nations, and the world.
\end{abstract}

Keywords: sustainability competencies; sustainability pedagogies; sustainability studies; sustainability studies program development; sustainability education; sustainability studies curriculum development; transdisciplinary education; sustainability learning outcomes

\section{Introduction}

Professors of sustainability studies and related transdisciplinary fields are among those answering an important calling of our time: to develop and offer quality academic programs that contribute meaningfully to addressing perhaps the most serious, sweeping, and integrated set of challenges humanity has ever known. We prepare our students to address converging socio-ecological crises that permeate virtually all facets of human life and institutions, as well as the natural world. At the same time, we are called to address the needs of graduates to find rewarding and well-compensated work in a world fraught with economic and employment instability, inequity, social division, and conflict. In full view of these challenges, it is imperative that we identify and teach the knowledge, skills, and abilities our graduates will most need to advance sustainability while confronting unprecedented change.

In this article, through a rigorous review of recently published sustainability field and sustainability education research and theory, I synthesize a competency-based foundation for sustainability studies, recommend potentially effective pedagogies for teaching these competencies, and share how the Bachelor of Arts in Sustainability Studies (BASS) faculty at Colorado Mountain College (CMC) is using my findings to evaluate and further develop BASS content, pedagogies, and learning outcomes. 
The application of my findings to the BASS program at CMC serves as a roadmap for other educators to apply/adapt my work for use in their specific institutional and programmatic contexts.

\section{Literature Review}

The fields of sustainability and sustainability education have developed and matured significantly in recent years, and a body of literature on competencies for the field has emerged, along with a body of work on effective sustainability pedagogies. Because my research represents an original amalgamation and distillation accomplished through rigorous and often detailed textual analysis of competencies and pedagogies mentioned/treated in the relevant literature, my approach to referencing sources in this article requires explanation. Due to the extensive number of sources reviewed for this study (over 100 texts), this literature review section serves as a vehicle for discussing only sources that served as foundations for formulating my thematic analysis/synthesis. Other sources not explicitly discussed in this section or elsewhere in the article, therefore, do not appear in my reference list. In order to offer a comprehensive list of the literature reviewed, I provide in Appendix D the full citations for every source consulted. My aim in this section is to focus on key sources while still referencing and honoring in Appendix D the full set of sources consulted.

\subsection{Literature on Sustainability Competencies for Higher Education}

Much recent work on sustainability competencies builds upon the work of Wiek and colleagues. Therefore, discussions of core competencies for sustainability program graduates must begin with reference to two important articles for which Wiek served as lead author [1,2]. Wiek, et al. [1,2], employed extensive literature review and synthesis to develop the following sustainability competencies:

1. Systems-thinking competence: the "ability to collectively analyze complex systems across different domains (society, environment, economy, etc.) and across different scales (local to global), thereby considering cascading effects, inertia, feedback loops and other systemic features related to sustainability issues and sustainability problem-solving frameworks" [1] (p. 207),

2. Anticipatory competence: "the ability to collectively analyze, evaluate, and craft rich 'pictures' of the future related to sustainability issues and sustainability problem-solving frameworks" [1] (pp. 207, 209),

3. Normative competence: "the ability to collectively map, specify, apply, reconcile, and negotiate sustainability values, principles, goals, and targets" [1] (p. 209),

4. Strategic competence: "the ability to collectively design and implement interventions, transitions, and transformative governance strategies toward sustainability" [1] (p. 210),

5. Interpersonal competence: "the ability to motivate, enable, and facilitate collaborative and participatory sustainability research and problem solving" [1] (p. 211), and

6. A "Meta-competence of meaningfully using and integrating the [other] five key competencies" to "[solve] sustainability problems and [foster] sustainable development" [2] (p. 243).

This framework has served as a point of departure and/or has served important formative roles in much recent work on formulating and teaching sustainability competencies [3-7]. My work, too, builds upon this set of competencies but revises the categories and descriptions in light of the unique insights made available to me through my grounded theory based approach to coding and my hermeneutically based textual analysis, my more recent literature review, and my past research and teaching praxis.

The work of Lozano and colleagues [6] served as another important foundation for developing my competencies framework. These authors undertook an extensive literature review that served as a basis for articulating 12 sustainability competencies. Their work breaks out some competencies that Weik and colleagues $[1,2]$ had combined in ways that could obscure some of their nuanced aspects. The work by Lozano and colleagues [6] also provides a bridge toward potential pedagogical pathways for competency development. My work in this article relates closely to that of Lozano, et al. [6], though my study is slightly more recent and is, therefore, able to build upon their findings while also drawing 
upon additional literature. The competency framework I develop remains closer to that developed by Wiek and colleagues [1,2] in terms of the number of key competencies identified. Like the work of Lozano, et al. [6], however, my competencies framework is informed by nuanced descriptions derived from my grounded theory based approach to coding, analyzing, and synthesizing themes from across the literature.

Stibbe's edited book [8] focuses directly on sustainability competencies, with each separatelyauthored chapter discussing an individual competency in some depth. Its chapters are based mostly on educators' expert reflections on praxis rather than on empirical research, but when insights gained from reviewing this work were compared to empirically grounded studies $[9,10]$, the importance of many, if not most, of the competencies covered was confirmed. The richness of the discussions of individual competencies in this text also added specificity to my conceptual framework of sustainability competencies.

Curtiss' [11] master's thesis identifies important sustainability competencies related to the sustainable development academic program at Sarvodaya's Institute of Higher Learning in Sri Lanka. The categories and themes outlined were important to refining the normative aspects of my competencies framework as well as competencies related to interpersonal and group communication/engagement.

Due to its rigorous synthesis, its international scope and its direct relevance to academic contexts, Reikman's [12] empirical study of expert knowledge and opinion on sustainability competencies and their application to higher education provided yet another launching point for identifying core sustainability competencies. Also, a report published by the United Nations Educational, Scientific and Cultural Organization (UNESCO) [13] on learning objectives related to sustainable development goals provided an important global scope for considering sustainability competencies for higher education. The UNESCO report aligned closely with the competencies developed by Wiek and colleagues $[1,2]$ and, ultimately, with the competencies I have articulated in this article.

\subsection{Literature on Sustainability Competencies from the Sustainability Profession}

Support for my sustainability competencies framework was greatly strengthened by drawing upon recent, competencies-focused, empirically grounded research published by the International Society for Sustainability Professionals [10,14]. The Association for the Advancement of Sustainability in Higher Education's technical manual for its sustainability tracking, assessment, and ratings system (STARS) program [15] for assessing institutional sustainability in higher education also provided important and current insights on the responsibilities and duties of institutional sustainability directors and coordinators, thereby indicating important competencies for sustainability practitioners. Knight's [9] master's thesis on behavioral competencies for sustainability leaders provided important insights specifically related to leadership for sustainability. Due to their empirical grounding and extensive scope, these resources greatly influenced my understanding of the knowledge, skills, and abilities most needed by sustainability professionals and thereby provided well-grounded insights related to sustainability competencies that should be taught in colleges and universities.

\subsection{Literature on General Competencies Needed for Employment Now and in the Future}

Because sustainability competencies reside within broader competency frameworks related to the successful transition of graduates from academic settings to professional work, I drew upon recent literature on how best to prepare students for long-term employability within the context of intensifying technological displacement of labor [16-21]. The knowledge, skills, and abilities most emphasized in these works, often collectively called "soft skills," overlapped with and provided additional support for the sustainability competencies framework I developed. These works also directed my attention toward soft skills and prompted me to review a recent empirical study highlighting the importance of soft skill development for new graduates [22]. Because sustainability work often requires soft skills for effective project management, leadership, and successful stakeholder engagement, I also drew upon the competence baseline developed by the International Project Management Association [23]. 
These resources offer important general insights on the knowledge, skills, and abilities needed by professionals in many fields, and especially by change agents working in diverse business, institutional, and community settings.

\subsection{Literature on Effective Sustainability Pedagogies}

In addition to developing a sustainability competencies framework, Lozano and colleagues, describe sustainability pedagogies and offer a summary of the varying potential of specific teaching approaches to foster the development of particular sustainability competencies [6] (p. 10). Their summary of sustainability pedagogies and the relative effectiveness of each in addressing sustainability competencies provided an important foundation for me to identify and evaluate sustainability pedagogies. Lozano, et al., found that problem/project-based pedagogy was one approach associated with fostering the broadest range of sustainability competencies [6] (p. 10). This insight parallels a central finding of this research discussed below. Smyth's [24] focus on critical thinking as a foundation for informed sustainability action, combined with my prior theoretical and research work $[25,26]$ on sustainability pedagogies influenced my inclusion of an explicitly articulated critical component within my sustainability competencies framework. Basing their empirical study of competency acquisition on the competency framework developed by Wiek, et al. [2], Trencher and colleagues studied the influence of master's-degree-level program type (practice-oriented, research-oriented, or neutral-a combination of both) on sustainability competency acquisition. Their finding that, in the area of developing knowledge and skills, programs that combine research and practice out-perform the other two program types in three out of five competency areas suggests the learning value of both research and practice in sustainability education [4] (p. 836). This specific finding informed my approach to curriculum and program revision/development at my institution. These sources stand out among others that contributed to my research on effective sustainability pedagogies.

Having reviewed a number of central sources and their influence on my research, we now turn to discuss my research methodology and methods for generating my sustainability competencies framework.

\section{Methodology and Methods}

My central purposes for this study are (1) to synthesize and describe in depth a framework of sustainability competencies that can serve as a foundation for academic programs in the field and (2) to develop a guiding pedagogical framework for effectively teaching these competencies. My research is based in an extensive and rigorous review of recently published international research and theory on sustainability competencies. I read more than 100 articles, books, chapters from books, theses, and reports identified through library database and open internet searches using the terms "sustainability" and "competencies" as well as variants of these and related words. Most sources included in my review were published within the last ten years. Sources published earlier were chosen based on their high relevance to my research as known to me through my extensive past engagement with their content. I did not sample the works identified but read and took notes on each source. I then used Excel spreadsheets to cite these sources and analyze their content. I also ranked sources to emphasize empirical grounding in research methodologies as well as relevance to sustainability competencies and/or pedagogies.

For textual analysis, my research process combined a grounded theory approach to coding and analyzing themes/concepts identified with hermeneutical interpretation of sources relative to each author's stated or implied audience and purposes. This approach allowed me to both synthesize thematic content from the literature and prioritize source relevance and reliability.

For phase one of my analysis, I developed a single Excel-based matrix for analyzing and coding each source. I then broke out two subject-based spreadsheets, one for competencies and one for pedagogies 
addressed in the literature. A third phase of analysis/synthesis called for the development of even more detailed and numerous spreadsheets, particularly for articulating sustainability competencies.

Following is a description of phase one of my textual analysis methodology through which I created my initial Excel-based matrix.

1. Source identification and organization:

a. Sources identified based on relevance to my research purposes; recent sources (past 10 years) emphasized.

b. Excel spreadsheet created for grounded theory and hermeneutical analysis and interpretation of the literature.

c. Sources cited and annotations for each made with regard to methodology and methods implemented, overarching content and purpose, relevant competencies identified, and pedagogical recommendations/implications.

2. Consideration of source methodology and methods as one vehicle for identifying the core literature for this study:

a. Using notes made on source methodology and methods, each source coded by tier $(1-5$, with 5 as the highest) with regard to its methodology (see Appendix A section on methodology that documents my ranking criteria); sources evidencing strong empirical support ranked higher than those lacking such support.

3. Consideration of source relevance and specificity as a second vehicle for identifying the core literature for this study:

a. Each source ranked regarding its relevance and specificity relative to subject(s) treated (competencies and/or pedagogies); rankings tiered (1-5, with 5 as the highest) (see Appendix A sections on competencies and pedagogies that document my ranking criteria).

4. Consideration of audience for sources as a third vehicle for identifying the core literature for this study:

a. Each source coded according to its stated or implied audience (sustainability field, sustainability field education, social change, and/or general education).

b. Rankings tiered according to relevance to informing sustainability competencies and pedagogy (see Appendix A section on audience that documents my ranking criteria).

5. Identification of core literature for this research:

a. By considering a combination of each source's methodology (with weighting positively influenced by empirical evidence offered and specificity provided) and relevance (subject and audience considered), sources ranked on a continuum ranging from core literature to literature that was mildly useful for this study.

6. Preparation for phase two of this study:

a. Sources, along with their respective notes and codes, sorted into two subject spreadsheets, one focused on sustainability competencies and one on pedagogies; sources addressing both subjects listed in both spreadsheets.

From this point forward, my two research purposes (developing a sustainability competencies framework and making recommendations on effective sustainability studies pedagogies) were best served by divergent research methods. In the following section, I discuss approaches I used to generate my sustainability competencies framework. The discussion of my methodology and methods associated with identifying potentially effective sustainability-oriented pedagogies appears below, integrated with discussion of my findings on that subject. 


\section{Sustainability Competencies Research}

\subsection{Methodology and Methods}

Following my initial analysis and coding performed in phase one of this research, I completed a more detailed analysis/synthesis of sustainability competencies that resulted in articulating five sustainability competencies: systems competency, critical and normative competency, interpersonal and communication competency, creative and strategic competency, and transdisciplinary competency. I then articulated overarching description statements for each competency and described in detail associated knowledge, skills, and attitudes/orientations. The five competencies and their descriptions appear in Figure 1. Diagrams for each individual competency, together with its description and cluster of integral knowledge, skills, and abilities/orientations, appear in Figures 2-6. Below, I describe the steps I employed to develop this competency framework:

1. Sources relevant to competencies grouped thematically and ranked (rankings done as part of phase one of this research; rankings based on source methodology and audience/subject relevance as described above).

2. Competency-focused sources placed into separate spreadsheets based on their content relevance to the following initial competency categories: overarching sustainability competency, systems competency, normative competency, critical and creative competency, interpersonal competency, strategic competency, and transdisciplinary competency.

3. Source content within competency subcategories examined in greater detail and depth to yield the following five finalized sustainability competencies: systems competency, critical and normative competency, creative and strategic competency, interpersonal and communication competency, and transdisciplinary competency.

4. Core competency descriptions drafted based on descriptions and examples from the literature.

5. Some knowledge, skill, and ability/orientation descriptions originally listed in one competency category transferred to another more relevant category.

6. Core competency category headings and descriptions placed in diagrams surrounded by examples/ descriptions of knowledge, skills, and attitudes/orientations that comprise/operationalize these competencies.

7. Content of competency diagrams reviewed and double checked against the competency-related content of the highest-ranking (most relevant and empirically grounded) sources consulted.

\subsection{Outcomes: Competencies Framework Development}

Diagrams depicting the outcomes of my sustainability competencies research appear in Figures 1-6. Figure 1 shows the five core sustainability competencies and their descriptions, while Figures 2-6 display the five competencies individually. In Figures 2-6, the blended shading for knowledge, skills, and abilities/orientations implies that there is no sharp division among these aspects of a given competency. The shading surrounding the competency title and its brief description (a complete blending of the two colors used to fill the larger area of the full competency diagram) also implies lack of sharp delineation among knowledge, skills, and abilities/orientations.

My competency framework, while similar and related to that developed by Wiek, et al. [1,2], offers important new insights based on additional syntheses and richly descriptive examples of knowledge, skills, and abilities/orientations that comprise/exemplify the competencies. Wiek and colleagues [1,2] also drew a distinction between systems competency and anticipatory competency. Since the knowledge, skills, and abilities/orientations needed for holistic forward thinking parallel the competencies for systems thinking (though applied to the future), I subsumed anticipatory competence as an aspect of systems competence. 


\section{Sustainability Field Core Competencies}

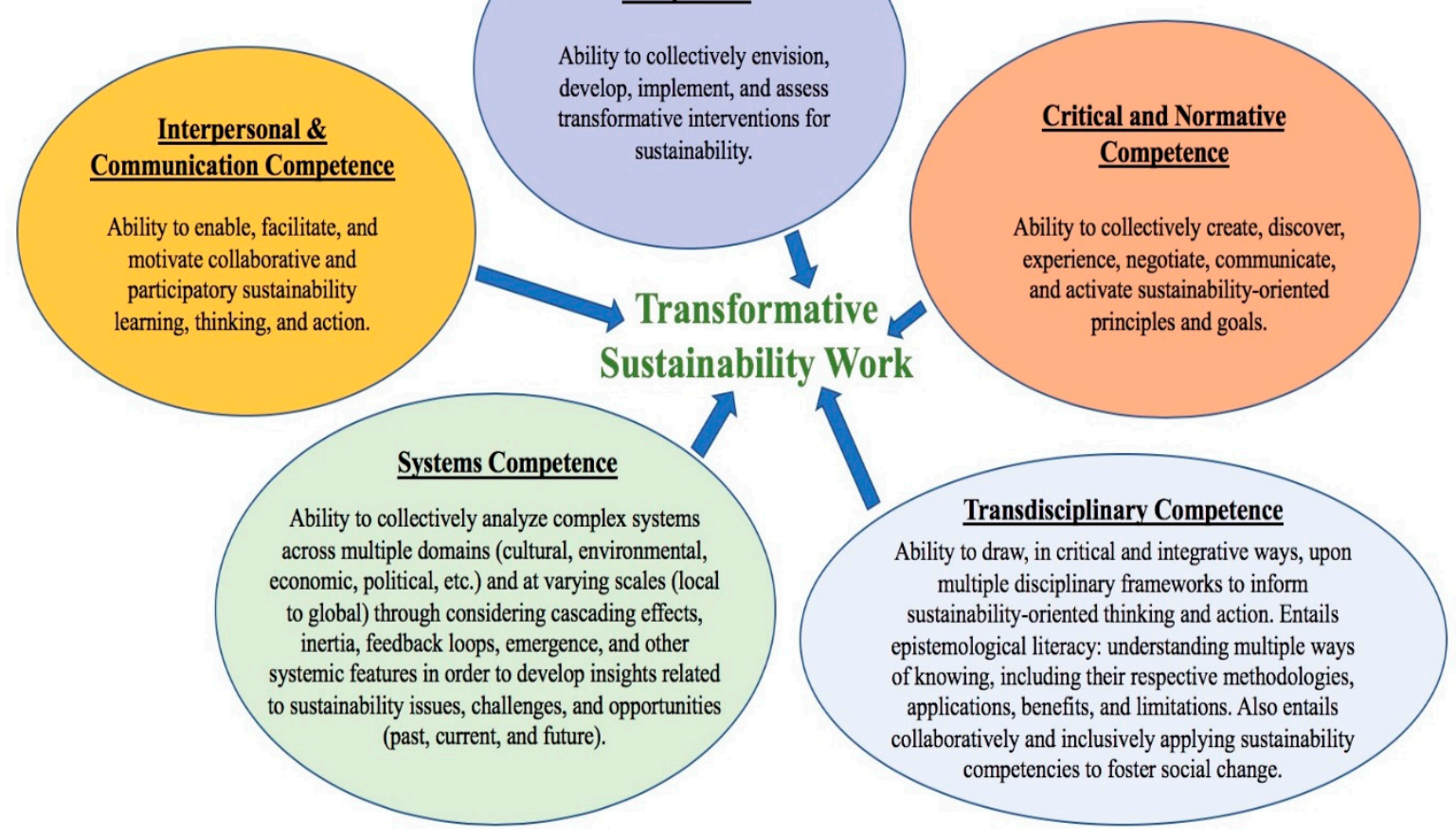

Figure 1. Core Sustainability Competencies.

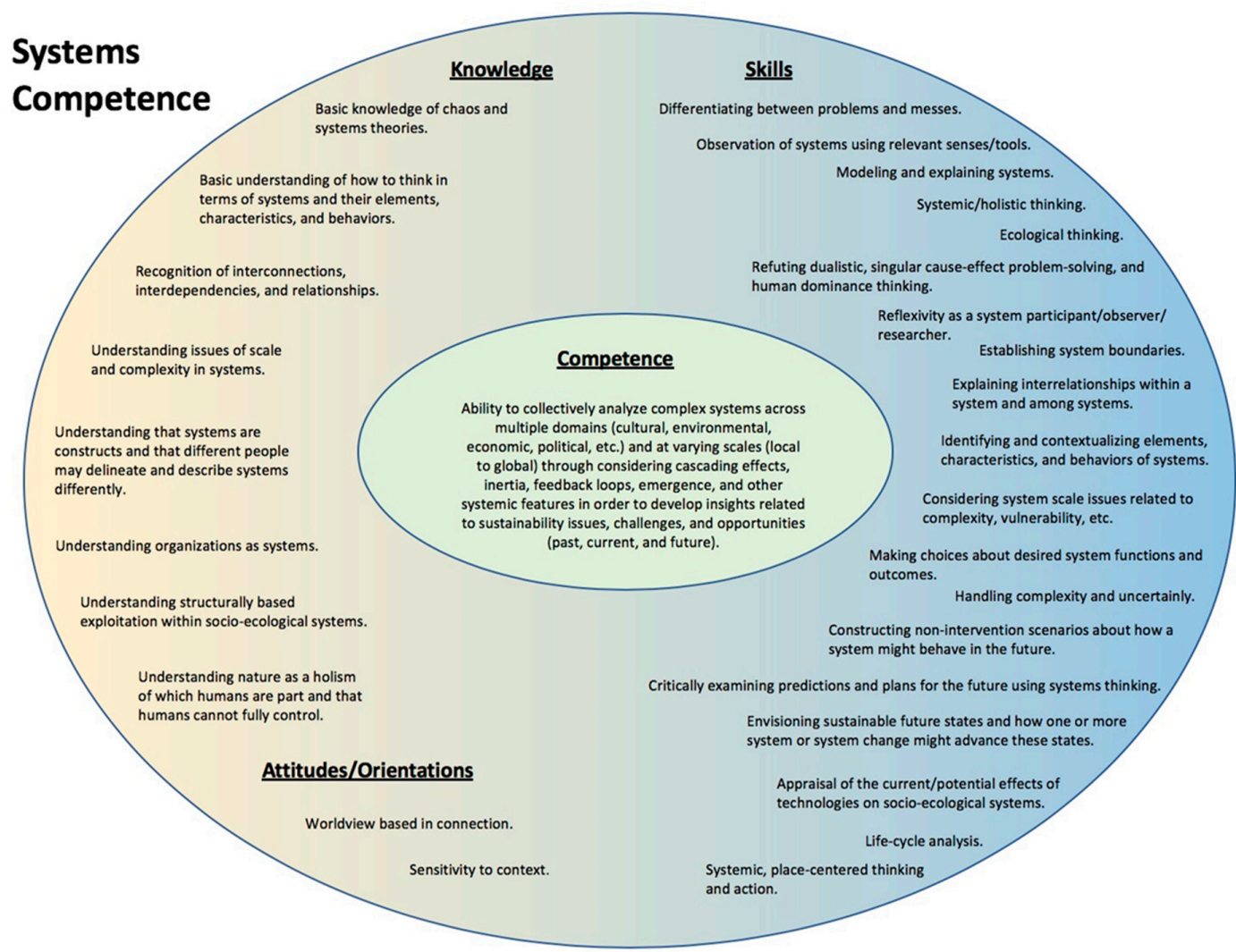

Figure 2. Systems Competence. 


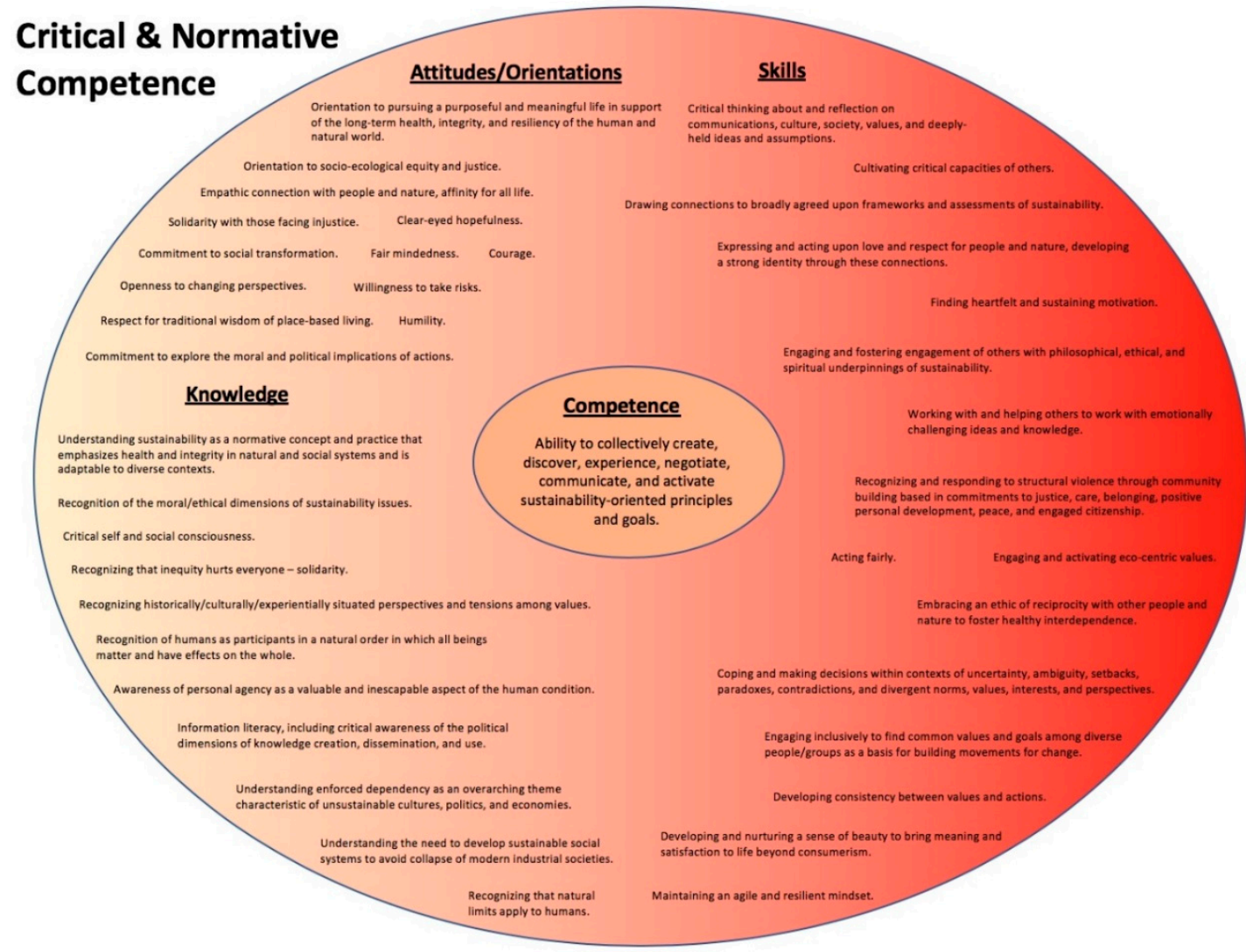

Figure 3. Critical and Normative Competence.

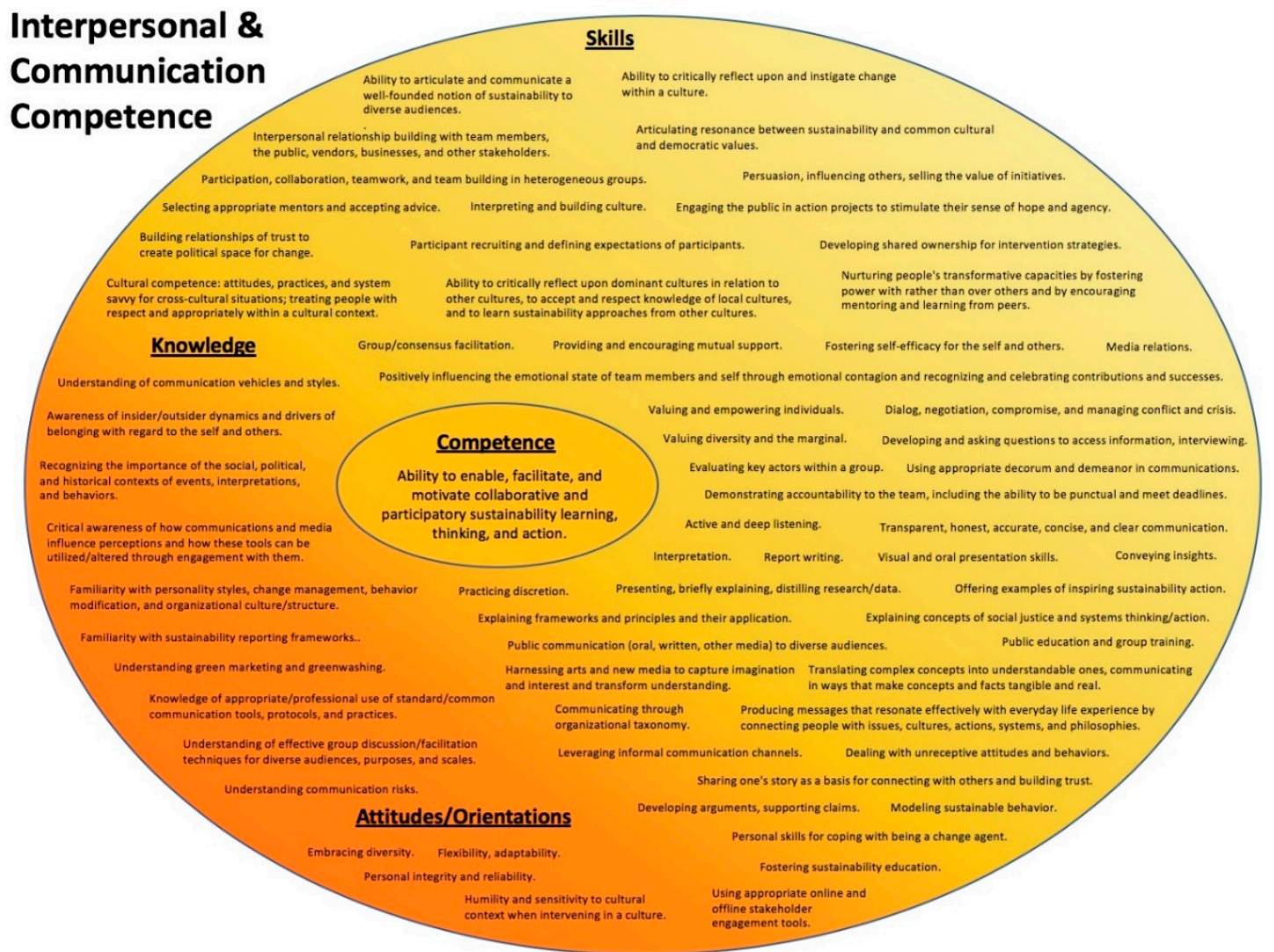

Figure 4. Interpersonal and Communication Competence. 


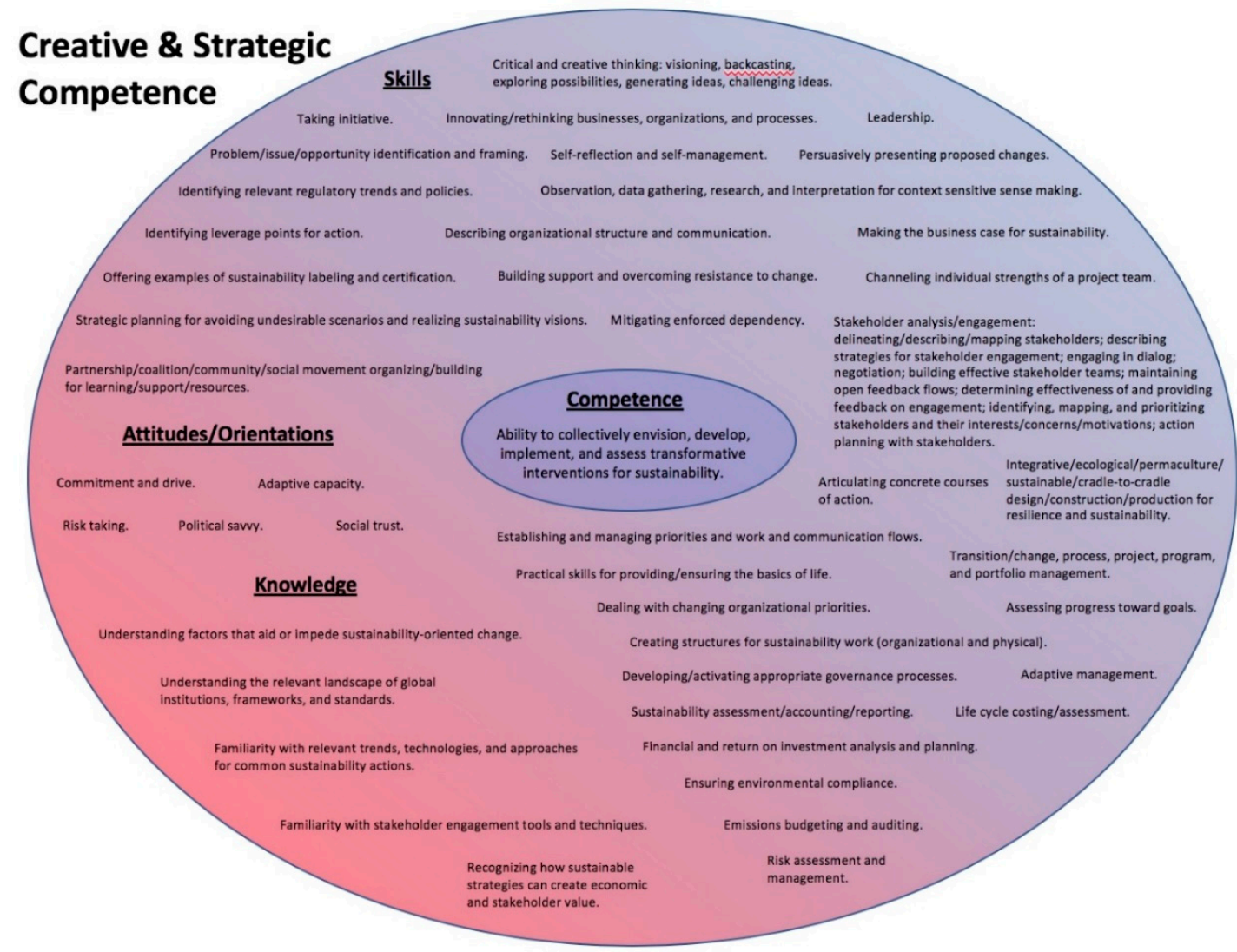

Figure 5. Creative and Strategic Competence.

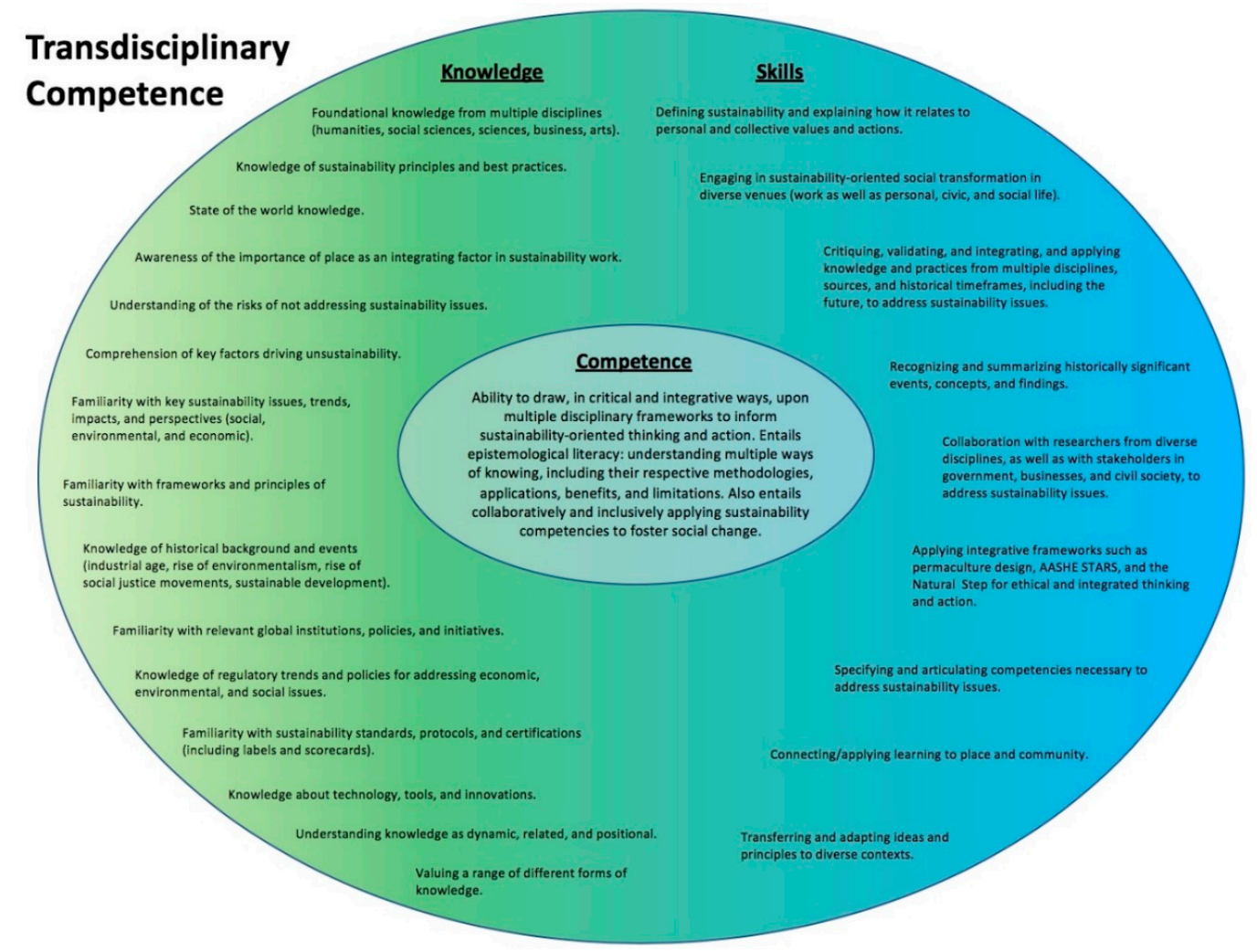

Figure 6. Transdisciplinary Competence. 
Like Wiek, et al. [1,2], I identified normative knowledge, skills, and abilities/orientations as central to sustainability competencies. Normative competency addresses the fundamental character of sustainability as a concept and practice: that it is about social change that entails creating new social norms. My literature review findings - including a review of my prior research and theory work in which I demonstrated criticality itself as a foundational step in generating social change along with the value of critical thinking and clear-eyed hope to effective sustainability education [25-27] prompted me to explicitly include a critical component to normative competency to create "critical and normative" sustainability competency.

Effective communication figured in the literature as perhaps the most often cited skillset needed by sustainability professionals. Of particular note, based on their extensive and empirically-grounded sustainability competency research, the International Society of Sustainability Professionals cited communication as a top competency for sustainability professionals [14]. I therefore expanded the Wiek, et al. [1,2], framework for interpersonal competency to explicitly include communication in its title, thereby creating "interpersonal and communication competency."

Because employing strategic competency for social change involves envisioning, planning, and scaffolding pathways to create something that does not yet exist, the strategic thinking or action-oriented competence articulated by Wiek, et al. [1,2], represents creativity at its core. Through my research, I also found that many areas of knowledge, skills, and abilities/orientations comprising strategic competency directly relate to innovating, creating alternative visions and plans, persuading, and leading - all of which require creative thinking and action toward effecting change. Therefore, I expanded the strategic thinking or action-oriented competency articulated by Wiek and colleagues $[1,2]$ to explicitly include creativity, naming the resulting competency area "creative and strategic competence."

The ability to meaningfully integrate other core sustainability competencies, articulated as itself a sustainability competency by Wiek, et al. [2], for me, became transdisciplinary competence. My earlier work on transdisciplinary education and theory [25,26,28-30] helped me to conceptualize this competency as transdisciplinarity. My work on program type definitions for mulit-, inter-, and transdisciplinary academic programs [28] highlighted, not only the integrative, but also the applied aspects of transdisciplinarity. This program definition work also emphasized that transdisciplinarity implies a critique of standard disciplinary divisions as it both confronts and transcends the limits of addressing real world problems from within the confines of traditional disciplinary methodologies. As a highly integrative, inclusive, critical, and applied field, sustainability is inherently transdisciplinary. Therefore, I titled this competency area "transdisciplinarity" and subsumed my original "overarching sustainability" competency category within it.

In contrast to the sustainability competencies framework developed by Lozano and colleagues [6], I chose to create fewer competency categories, though the highly valuable content of each of the 12 categories developed by Lozano, et al., influenced my five categories and their descriptions. Through adapting/creating my five competency areas, I was able to offer a concise foundation for the BASS faculty to articulate a limited number of related program-level learning outcomes in service to program development and assessment. I discuss the development of these outcomes in the following section. It is my hope that the sustainability competency framework developed through my research, together with my description of its application to a specific academic program, can serve as a partial or adaptable roadmap for similar work undertaken in service to program development at other institutions.

\subsection{Outcomes: Course and Program Development at Colorado Mountain College}

My research was aimed at improving the relevance and graduate outcomes of CMC's Bachelor of Arts in Sustainability Studies program as well as at contributing to the field of sustainability education more broadly. In service to BASS program development, I mapped the program's core (required) course descriptions and learning outcomes to the competency descriptions/examples shown in Figures 2-6. I took the following steps to create these maps: 
1. BASS core course descriptions and outcomes gathered into one Word document (see Appendix B).

2. Learning outcomes for all BASS core courses examined and compared to competency framework content shown in Figures 2-6.

3. Course numbers added to knowledge, skills, and abilities/orientations statements within each competency diagram wherever the course outcomes and/or description closely aligned with these statements.

Figures 7-11 depict the five competency diagrams that include BASS core course number mapping. Course numbers are included directly above closely aligned knowledge, skills, and abilities/orientations statements. Through this mapping process, I identified program strengths and gaps relative to my sustainability competencies framework.

I shared and discussed Figures 7-11 with the BASS core faculty at its fall 2018 program assessment meeting. The faculty recognized that the BASS program is generally well conceived with regard to addressing sustainability competencies. The faculty also identified curricular gaps relative to two competencies: (1) creative and strategic competency and (2) interpersonal and communication competency. More specifically, the faculty discussed an important need documented in my research: to improve competency development related project management, stakeholder engagement, and collaboration within the context of organizational change.

The identification of competencies not currently well addressed in our program prompted me to propose an additional Communication course prerequisite for the BASS at the lower division level. Further consideration of this proposal will continue in fall 2019. My findings also prompted me to draft a course proposal for a new required Sustainability Studies course: Sustainability Studies (SUS) 450, Sustainability Assessment and Reporting. The course proposal is currently under consideration by the BASS faculty. Its proposed rationale, description, learning outcomes, and topical outline are included here as Appendix C. Note that, in an effort to demonstrate how this proposed course could address competency gaps in the BASS curriculum, SUS 450 is included in Figures 7-11.

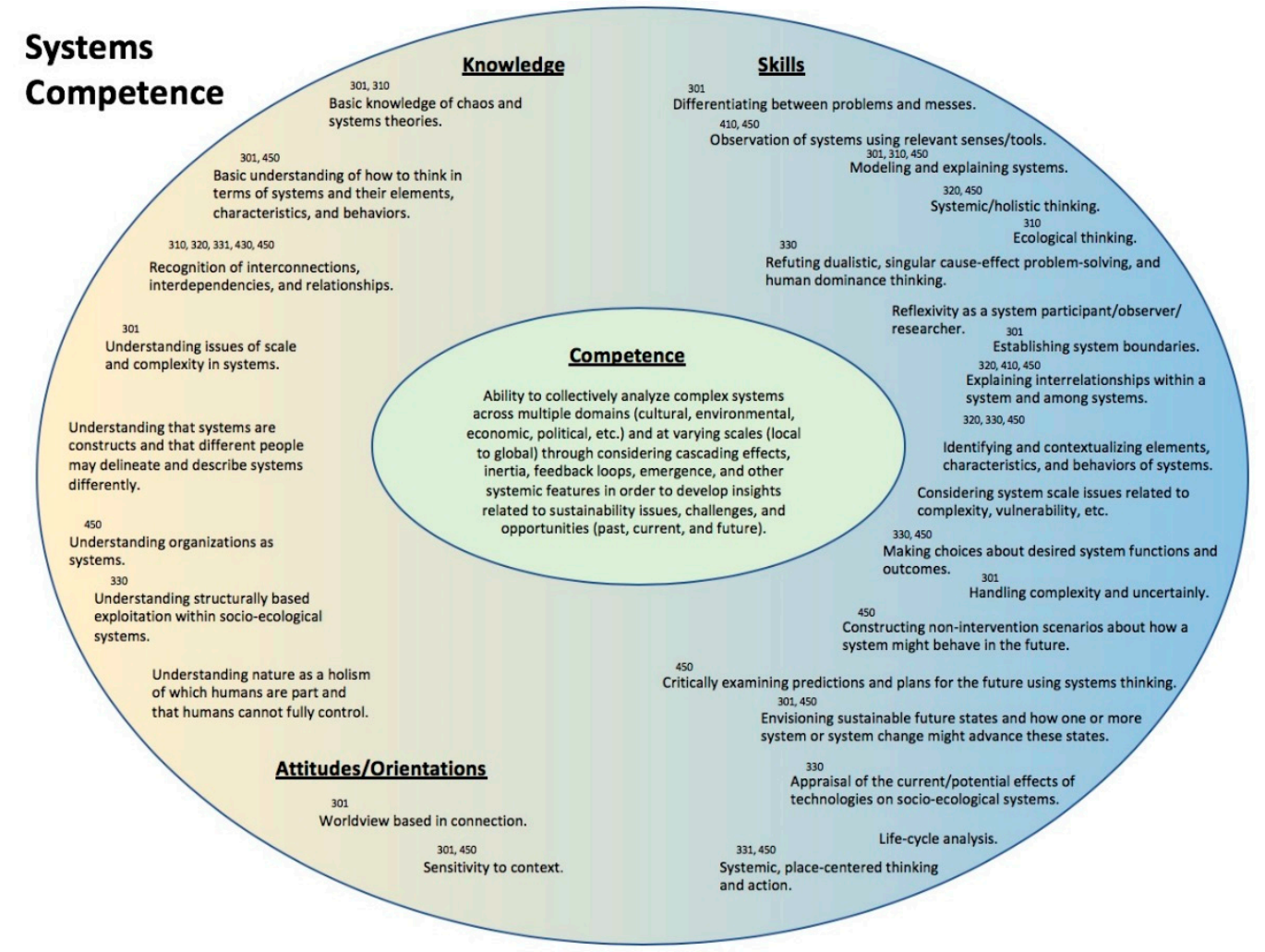

Figure 7. Systems Competence with CMC Sustainability Studies Course Learning Outcomes Mapping. 


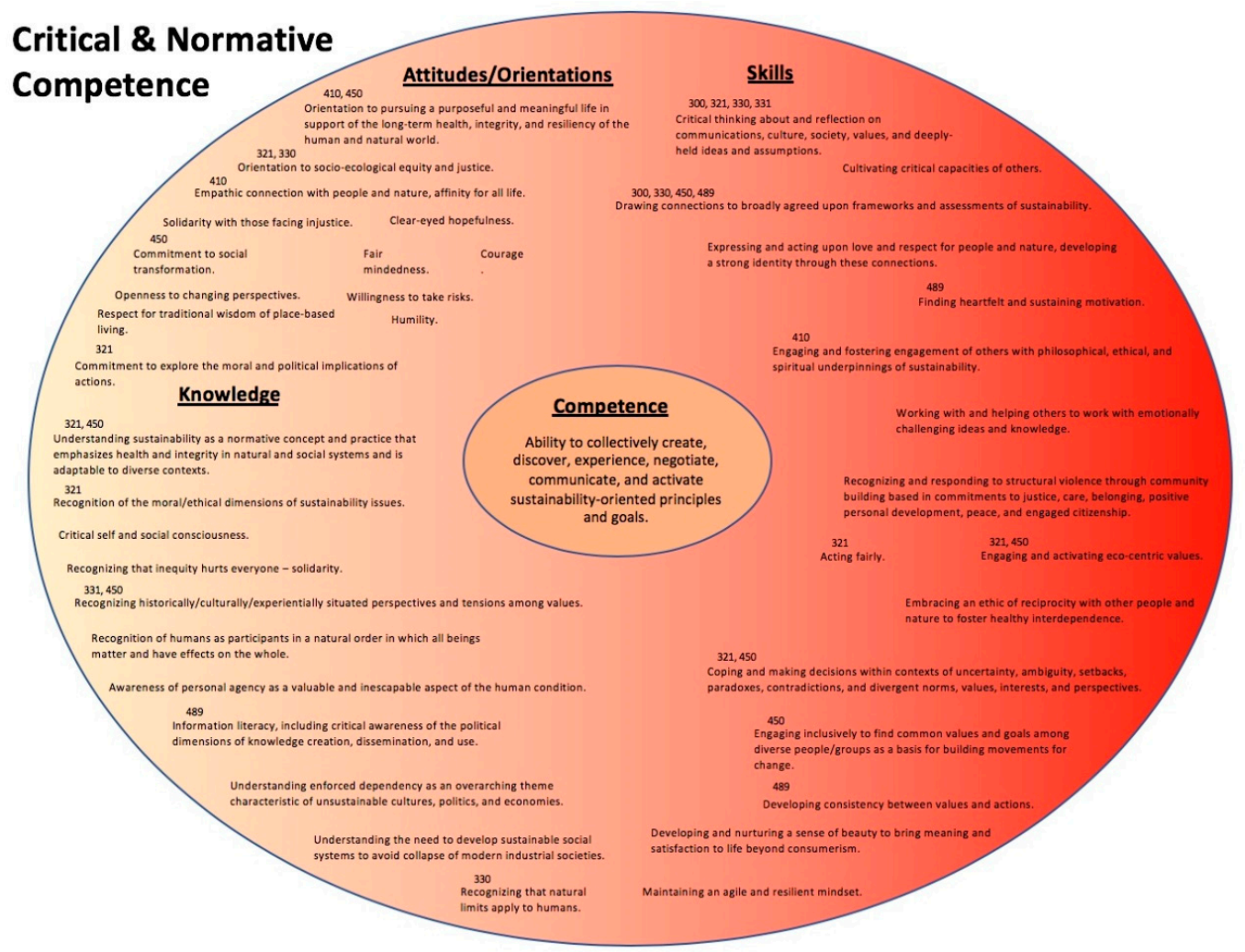

Figure 8. Critical and Normative Competence with CMC Sustainability Studies Course Learning Outcomes Mapping.

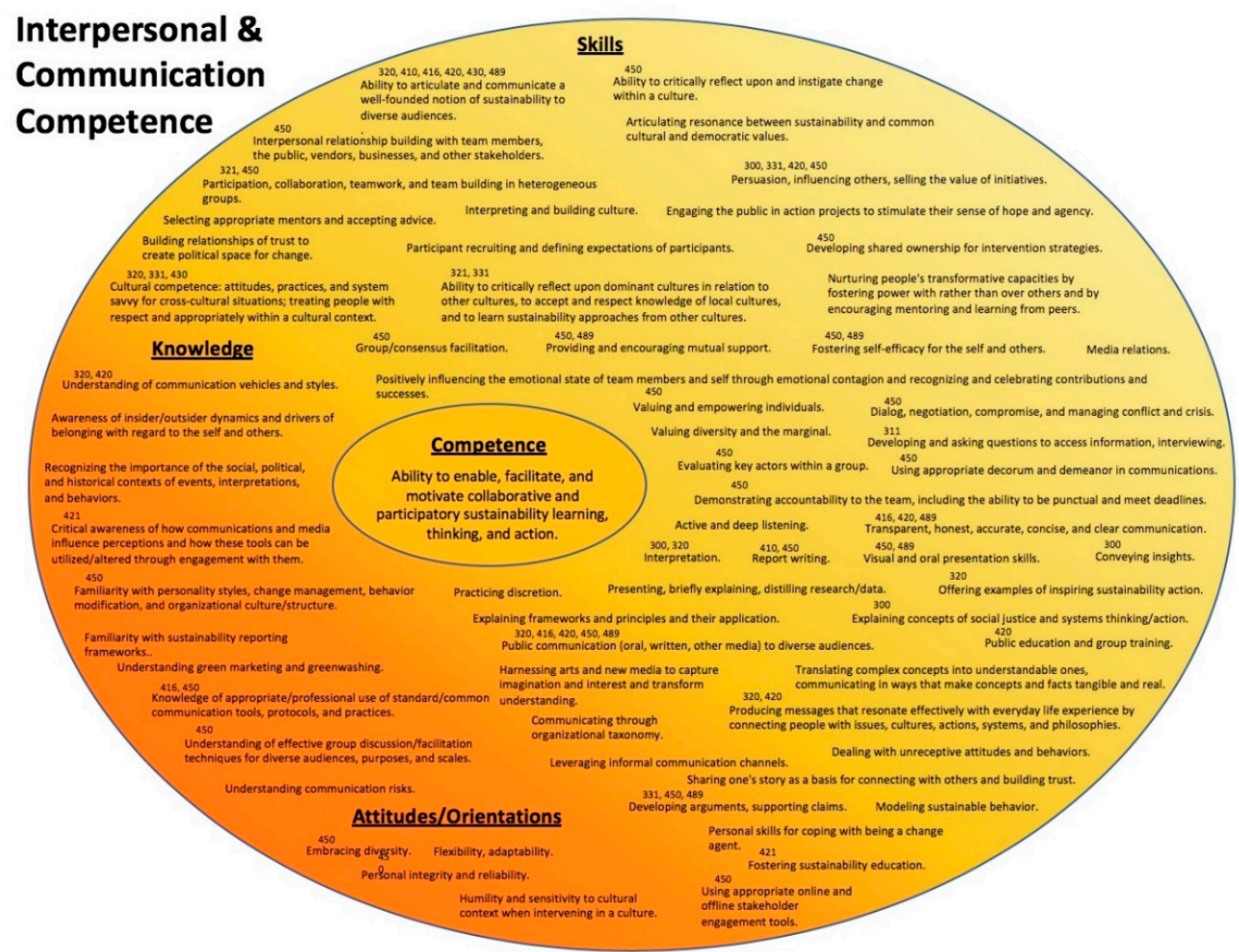

Figure 9. Interpersonal and Communication Competence with CMC Sustainability Studies Course Learning Outcomes Mapping. 


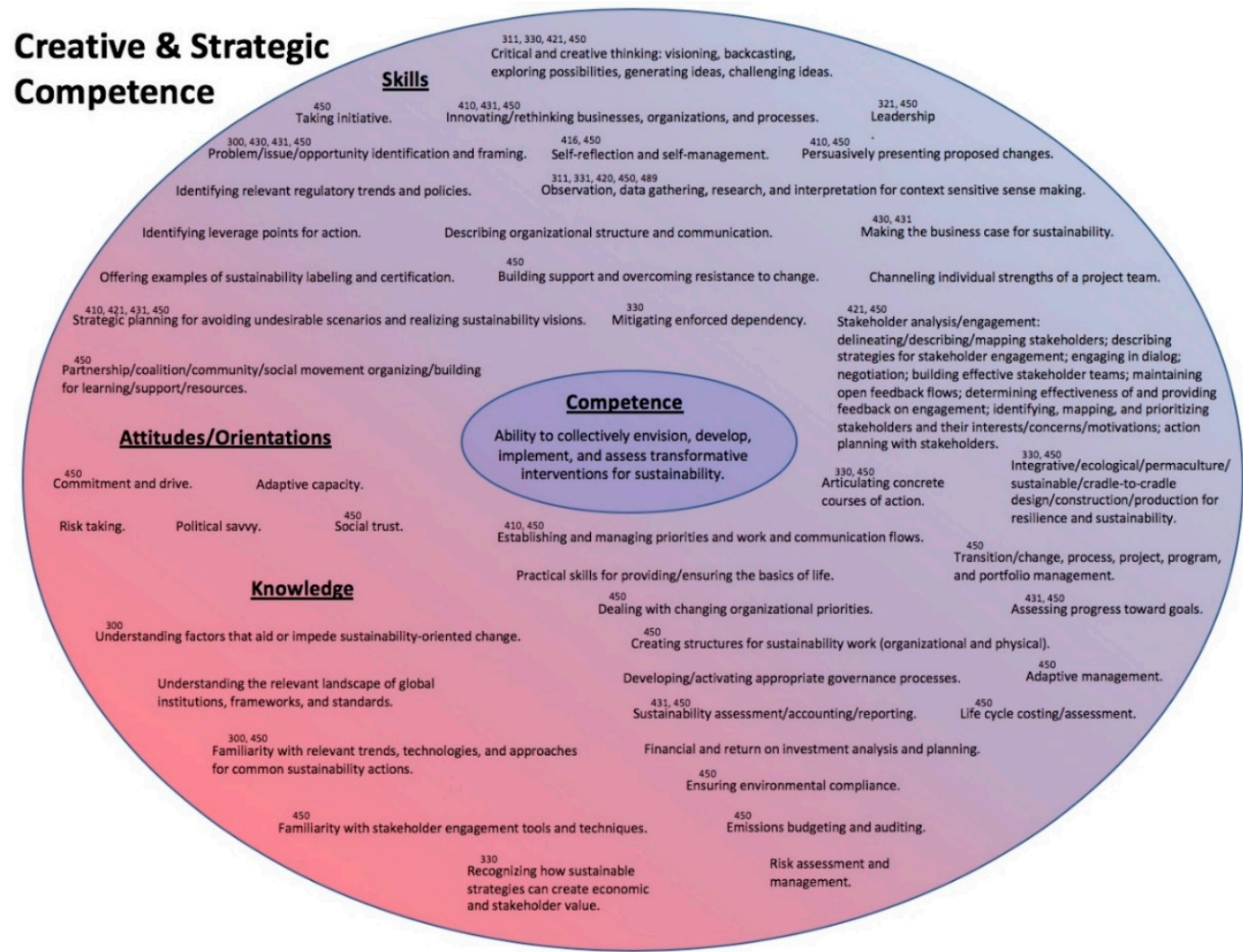

Figure 10. Creative and Strategic Competence with CMC Sustainability Studies Course Learning Outcomes Mapping.

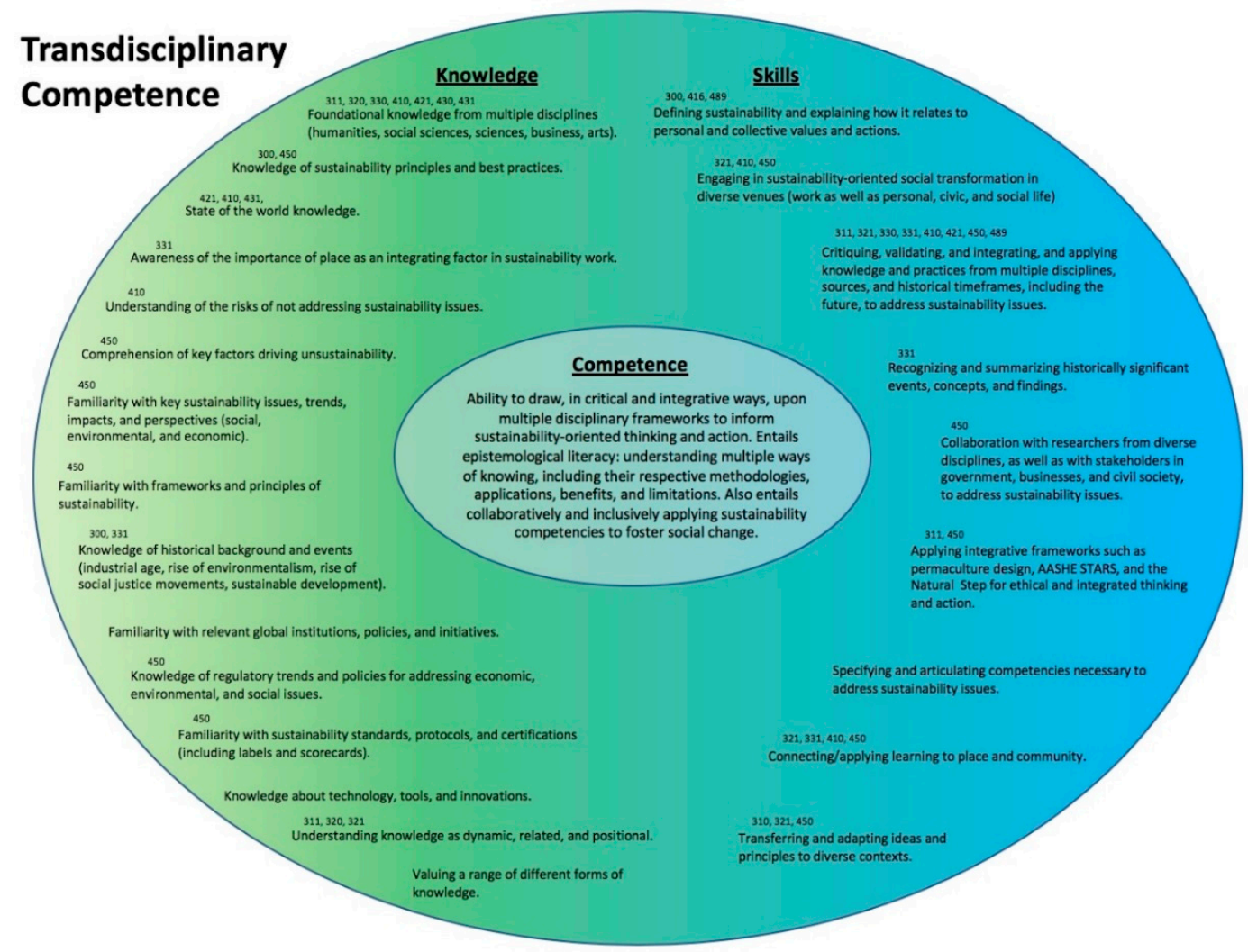

Figure 11. Transdisciplinary Competence with CMC Sustainability Studies Course Learning Outcomes Mapping. 
My research also prompted me to engage the BASS faculty in a revision of program-level learning outcomes. Following is the revised set of outcomes the faculty developed:

Upon completion of the Sustainability Studies B.A. program at Colorado Mountain College, graduates should be able to:

1. Articulate the concept and practice of sustainability as it relates to the self, community, and the wider world.

2. Analyze, synthesize, and interpret complex adaptive systems.

3. Conduct and communicate sustainability research that draws upon, integrates, critiques, and/or transcends disciplinary frameworks.

4. Demonstrate how qualitative/quantitative measures can be used in collaboration with diverse stakeholders to assess, report, and design approaches that address sustainability challenges and opportunities.

5. Demonstrate professional skills and career development abilities in the field.

Appendix E contains additional notes related to enhancing the teaching of specific competencies in the BASS at CMC. Those notes will continue to inform BASS faculty discussions of potential curriculum changes.

This research has contributed productively to BASS course and program development. Because the world needs more and continually improving sustainability education everywhere, I hope my work will also contribute to course and program development initiatives at other institutions.

We now turn to discuss my research on sustainability-oriented pedagogies. Since the methodology and methods applied in this portion of my research diverge from those utilized in developing my sustainability competency framework, I begin with discussing my approach to identifying potentially effective sustainability pedagogies.

\section{Sustainability Pedagogies Research}

\subsection{Overview}

As a distinct part of this research, I studied pedagogical approaches for sustainability studies programs recommended in the relevant literature. My research on pedagogy was secondary to my research on sustainability competencies. As I reviewed and annotated the literature on sustainability competencies, I also analyzed/synthesized recommended pedagogies that I encountered within the literature on competencies. I also located and reviewed some sources that focused primarily on sustainability studies pedagogies. For a full listing of sources reviewed, see Appendix D. In this section, I articulate my findings with regard to recommended sustainability pedagogies and utilize these findings as a springboard for making recommendations for maintaining/enhancing specific pedagogical approaches for the BASS.

\subsection{Methodology}

Citations for sources in which pedagogy was addressed were entered into an Excel spreadsheet and sorted according to their relevancy rankings with regard to pedagogical recommendations. Five tiers of relevancy were utilized with tier five representing the strongest relevance and tier one the weakest. See pedagogy section of Appendix A for my ranking framework.

References to pedagogies within sources reviewed totaled 172. I categorized these references into the following sixteen distinct pedagogical approaches that I synthesized/developed based on holistic reflection on the literature and my professional experience. That synthesis appears in Table 1. 
Table 1. Pedagogical Approaches for Sustainability Studies.

\begin{tabular}{|c|c|}
\hline Pedagogical Approach & Description/Example(s) \\
\hline $\begin{array}{l}\text { Project/problem-based } \\
\text { learning (in an } \\
\text { organization/community) }\end{array}$ & $\begin{array}{l}\text { Learning through actively attempting to study/address a community/organizational } \\
\text { problem or undertake a project deemed necessary/useful by the } \\
\text { class/community/organization. }\end{array}$ \\
\hline $\begin{array}{l}\text { Project/problem-based } \\
\text { learning (in class) }\end{array}$ & $\begin{array}{l}\text { Simulations that mimic actively attempting to study/address a community/organizational } \\
\text { problem - undertaking an individual/group/class project deemed by the student(s) and } \\
\text { professor to be necessary and useful within a known context but without engaging or by } \\
\text { only minimally engaging stakeholders outside the class. }\end{array}$ \\
\hline Active learning (in class) & $\begin{array}{l}\text { Learning in which students are actively involved in constructing meaning, making } \\
\text { interpretations, and/or applying knowledge-contrasts with passive learning in which } \\
\text { students receive content and are expected to internalize and recall that content in basically } \\
\text { unchanged form. }\end{array}$ \\
\hline Collaborative learning & $\begin{array}{l}\text { Learning that involves active collaboration with classmates, community members, and/or } \\
\text { others to generate/explore/analyze/interpret/apply ideas/practices. }\end{array}$ \\
\hline Experiential learning & $\begin{array}{c}\text { Learning through doing in a very broad sense-can serve as an overarching category that } \\
\text { includes a number of other pedagogies listed here. }{ }^{1}\end{array}$ \\
\hline $\begin{array}{l}\text { Integrative learning (inter- } \\
\text { and transdisciplinary) }\end{array}$ & $\begin{array}{l}\text { Integrating knowledge/methodologies/methods from more than one disciplinary } \\
\text { framework to understand/address complex and context-sensitive issues-contextualizing } \\
\text { knowledge and action within relevant socio-ecology. }\end{array}$ \\
\hline Reflexive learning & $\begin{array}{l}\text { Metacognitive reflection on learning to reveal relevant learning processes/content and to } \\
\text { situate the meaning of what is learned relative to the self and the wider world. }\end{array}$ \\
\hline $\begin{array}{l}\text { Critical text/information } \\
\text { analysis }\end{array}$ & $\begin{array}{l}\text { Critical examination of texts/information aimed at revealing/interpreting the } \\
\text { influence/presence of social power constructs, biases, cultural constructs, and } \\
\text { epistemologies with regard to their associated implications for both societies and nature. }\end{array}$ \\
\hline Service learning & $\begin{array}{l}\text { Learning in which students address real-world issues while receiving support for their } \\
\text { actions through studying relevant material in the classroom-ideally benefits a } \\
\text { community/organizational partner while also creating powerful opportunities for active } \\
\text { learning for students. }\end{array}$ \\
\hline $\begin{array}{l}\text { Internships and } \\
\text { apprenticeships }\end{array}$ & $\begin{array}{l}\text { Learning that occurs through students undertaking real-world training/work within } \\
\text { organizational settings outside the classroom—-training/work is ideally closely related to } \\
\text { the student's field of study. }\end{array}$ \\
\hline Research-based learning & $\begin{array}{l}\text { Learning that occurs through individual students or groups of students undertaking } \\
\text { primary and/or secondary research to address identified questions/issues. }\end{array}$ \\
\hline Creative work/expression & $\begin{array}{l}\begin{array}{l}\text { Invention and/or creative communication/representation of ideas, processes, relationships, } \\
\text { emotions, etc. }\end{array}\end{array}$ \\
\hline Case studies & $\begin{array}{l}\text { Reading about, viewing visual material about, and/or directly observing one or more } \\
\text { process/issue at work within a particular context-involves } \\
\text { analyzing/synthesizing/interpreting the process/issue as it changes/evolves/unfolds within } \\
\text { a particular context and may involve making recommendations to improve the } \\
\text { process/issue as related to specific people, groups, organizations, and/or nature. }\end{array}$ \\
\hline $\begin{array}{l}\text { Discussion-based } \\
\text { learning }\end{array}$ & $\begin{array}{l}\text { A process of using discussion to explore/understand issues, ideas, cases, etc.-can serve as } \\
\text { an approach that supports many other pedagogies, and so, may not be mentioned } \\
\text { explicitly within descriptions of other recommended active pedagogies. }{ }^{2}\end{array}$ \\
\hline Learning communities & $\begin{array}{l}\text { Two or more courses that are co-required and that mutually support student } \\
\text { learning-typically aimed at addressing identified themes or issues, often } \\
\text { inter/transdisciplinary in orientation. }\end{array}$ \\
\hline $\begin{array}{l}\text { Writing-intensive } \\
\text { learning }\end{array}$ & $\begin{array}{l}\text { Learning that occurs through the process of writing-may involve research, critical } \\
\text { thinking, and/or reflection activities as central vehicles for developing insights and } \\
\text { understandings. }\end{array}$ \\
\hline
\end{tabular}

Mentions/discussions of specific pedagogical approaches were noted for each source. Initially, the total number of sources that referenced each pedagogy was tallied regardless of the tiered relevancy rankings of the sources from which these references derived. A mention by a source of a given pedagogy was counted only once, rather than counting each instance in which the pedagogy was 
referenced by name or in an example within one source. This approach allowed me to reveal the number of sources that recommended a particular pedagogy rather than the number of times within the sources the pedagogy was mentioned. This approach yielded more meaningful insights in terms of interpreting how widespread a particular pedagogical recommendation was across the sustainability education literature reviewed. A separate measure of the quality/depth of these references was also undertaken and is discussed below.

Recommended pedagogies were then ranked as having a probable high, medium, or low priority based on the percentage of mentions each received relative to the total of 172 references to pedagogies. References to probable high-priority sources ranked at around $10 \%$ or higher relative to total references to pedagogies. Medium priority pedagogies were referenced in approximately $4-9 \%$ of sources relative to the total, and low priority pedagogy references comprised approximately $2-3 \%$ of the references. The resulting rankings of pedagogical approaches appears in Table 2.

Table 2. Initial Prioritized Rankings for Sustainability Studies Pedagogies.

\begin{tabular}{|c|c|}
\hline Pedagogical Approach & $\begin{array}{c}\text { Total Number of References } \\
\text { across Sources }\end{array}$ \\
\hline \multicolumn{2}{|l|}{ Probable High-Priority Approaches } \\
\hline Project/problem-based learning (in an organization/community) & 26 \\
\hline Active learning (in class) & 23 \\
\hline Collaborative learning & 21 \\
\hline Experiential learning & 19 \\
\hline Project/problem-based learning (in class) & 17 \\
\hline Integrative learning (inter- and transdisciplinary) & 18 \\
\hline \multicolumn{2}{|l|}{ Probable Medium Priority Approaches } \\
\hline Reflexive learning & 14 \\
\hline Critical text/information analysis/interpretation & 12 \\
\hline Service learning & 8 \\
\hline Internships and apprenticeships & 8 \\
\hline Research-based learning & 7 \\
\hline Creative work/expression & 6 \\
\hline \multicolumn{2}{|l|}{ Probable Low Priority Approaches } \\
\hline Case studies & 5 \\
\hline Discussion-based learning & 4 \\
\hline Learning communities & 3 \\
\hline Writing-intensive learning & 2 \\
\hline
\end{tabular}

In order to offer an additional, quality-based rationale for categorizing pedagogical approaches as high, medium, or low priority for sustainability studies programs, I examined the tiered relevancy rankings of the specific sources advocating each pedagogy. My approach entailed calculating the percentage of references to each pedagogical approach that derived from high relevancy sources (tiers five and four of the pedagogies ranking criteria; see Appendix A). Approaches for which approximately $65 \%$ of the references derived from high relevance sources were classified as demonstrating high confidence with regard to the merit of the sources referencing the approach. Note that, for this research, high confidence in the merit of the source material does not necessarily indicate that a pedagogy is a high priority for sustainability education, though a high confidence rating does favorably influence a pedagogy toward being recognized as valuable. 
Pedagogical approaches with both high confidence ratings and probable high relevance rankings were identified. These pedagogies totaled five of the 16 approaches analyzed. Note that project/problem-based learning was referenced a total of 43 times in two distinct categories, far outpacing any other pedagogy discussed. This pedagogy also displayed high confidence with regard to source references. The results of this ranking process appear in Table 3.

Table 3. High Relevance and High Confidence Sustainability Studies Pedagogies.

\begin{tabular}{ccc}
\hline Pedagogical Approach & Total Number of References & Confidence Percentile \\
\hline $\begin{array}{c}\text { Project/problem-based learning (in an } \\
\text { organization/community) }\end{array}$ & 26 & $72 \%$ \\
\hline $\begin{array}{c}\text { Integrative learning (inter- and } \\
\text { transdisciplinary) }\end{array}$ & 18 & $72 \%$ \\
\hline Project/problem-based learning (in class) & 17 & $71 \%$ \\
\hline Active learning (in class) & 23 & $68 \%$ \\
\hline Collaborative learning & 21 & $65 \%$ \\
\hline
\end{tabular}

Pedagogical approaches with high confidence ratings coupled with probable medium level relevance were also identified. These pedagogies total four of the 16 approaches analyzed. The outcomes of this ranking process appear in Table 4.

Table 4. Medium Relevance and High Confidence Sustainability Studies Pedagogies.

\begin{tabular}{ccc}
\hline Pedagogical Approach & Total Number of References & Confidence Percentile \\
\hline Service learning & 8 & $100 \%$ \\
\hline Research-based learning & 7 & $100 \%$ \\
\hline $\begin{array}{c}\text { Critical text/information } \\
\text { analysis/interpretation }\end{array}$ & 12 & $92 \%$ \\
\hline Reflexive learning & 14 & $86 \%$ \\
\hline
\end{tabular}

Seven pedagogical approaches fell outside the high confidence ratings and/or were deemed as probable low relevance approaches due to low numbers of source references to them. These rankings are summarized in Table 5.

Table 5. Relatively Low Relevance and/or Confidence Sustainability Studies Pedagogies.

\begin{tabular}{ccc}
\hline Pedagogical Approach & Total Number of References & Confidence Percentile \\
\hline Discussion-based learning & 4 & $100 \%$ \\
\hline Writing intensive learning & 2 & $100 \%$ \\
\hline Case studies & 5 & $80 \%$ \\
\hline Experiential learning & 6 & $68 \%$ \\
\hline Creative work/expression & 6 & $67 \%$ \\
\hline Learning communities & 3 & $67 \%$ \\
\hline Internships and apprenticeships & 8 & $50 \%$ \\
\hline
\end{tabular}

5.3. Interpretation of Findings and Their Relevance for the BASS at CMC

\subsubsection{Value of the Top Nine Pedagogical Approaches}

The top nine pedagogical approaches for effective BASS instruction identified through my research were: 
1. Project/problem-based learning (in an organization/community),

2. Integrative learning (inter- and transdisciplinary),

3. Project/problem-based learning (in class),

4. Active learning (in class),

5. Service learning,

6. Research-based learning,

7. Critical text/information analysis/interpretation,

8. Reflexive learning, and

9. Collaborative learning.

Sustainability Assessment and Reporting (SUS 450), proposed for addition to the CMC BASS required curriculum (see Appendix C), could utilize all or nearly all of these pedagogical approaches. Therefore, in addition to providing a platform for addressing key sustainability field competencies that are currently underdeveloped in the BASS, this course could prove to be a significant pedagogical improvement for the program. SUS 450 would be an active learning, project-based course with a focus on integrative knowledge-making/learning, intensive collaboration in project teams, and stakeholder engagement. The course would also represent a form of service learning as it would serve the needs of an organization, and it would require extensive research as well as analysis and interpretation of information and communications. The course would also require reflection on one's own and others' contributions to collaborative processes of project management. This course would bring a great deal to the program in terms of developing students' sustainability competencies and doing so through highly effective pedagogical approaches. SUS 450 represents an important potential evolution of the BASS program to address competency development for the sustainability field through engaging students in meaningful, richly experiential learning opportunities. Similar courses might be considered for sustainability programs at other institutions.

\subsubsection{Value of the Bottom Seven Pedagogical Approaches}

Of the seven pedagogical approaches that fell outside the high confidence/high-to-medium relevance rankings, most appear to be worth applying in the BASS because they are often embodied in other forms of learning that are ranked more highly in this research in terms of source confidence and total references by sources reviewed. The following is a brief discussion of the bottom seven pedagogies relative to their current/potential roles in the BASS.

- Discussion-based learning is an approach that may be subsumed within other pedagogies such as active learning, project-based learning, service learning, and critical text/information analysis/interpretation. Discussion-based learning may be seen as a teaching and learning technique rather than an overarching pedagogical framework. It can be very useful in the BASS, especially when applied within another pedagogical framework highly relevant to developing BASS competencies.

- Writing-intensive learning is an important active learning pedagogy. The BASS adopted a writing across the curriculum (WAC) initiative in response to 1) poor writing outcomes observed in early program assessment results and 2) the perceived need for sustainability professionals to communicate effectively with diverse audiences. Since my research findings on sustainability competencies highlight effective communication as perhaps the most important competency for success in the sustainability field, writing-intensive learning embodied in the BASS WAC initiative should continue.

- Case studies can be effective components of larger projects and should be highlighted as effective vehicles for generating ideas to address project-based learning goals and challenges. Case studies are also effectively part of many service learning projects in which the work of students for a group/organization is meaningfully contextualized to help students make sense of their efforts relative to a particular case. 
- Experiential learning is an overarching category that includes project/problem-based learning, service learning, collaborative learning, and research-based learning. Other pedagogies recommended for the BASS represent diverse forms of experiential learning.

- Creative work/expression is an inherent activity within project/problem-based learning that seeks to adapt/invent ways to address challenges and opportunities. This form of learning is also an integral component of inter- and transdisciplinary learning that uses critical and creative thinking to adapt/develop appropriate arguments and actions to specific contexts. Creative work/expression is also a form of active learning, and it can be applied to service learning, research-based learning, critical text/information analysis/interpretation, collaborative learning, and reflexive learning. Creative work/expression should become an explicit avenue for activating and enhancing a number of the high confidence/high-to-medium relevance pedagogies identified in this research.

- Learning communities are resource and time-intensive activities that can serve as powerful vehicles for inter- and transdisciplinary active learning. I know this well having taught in and served as a director for a $12-15$ credit, sustainability-oriented learning community for a number of years and also having developed and offered a two-course sustainability learning community for incoming freshmen at CMC. Perhaps one of the reasons this pedagogy is not often mentioned in the literature I reviewed is because of its high demands on resources, particularly faculty time, that may effectively reduce the scope of its application. As long as the BASS program has the resources to support these efforts, faculty members can and should create and run learning communities, but these efforts should not slow or supplant efforts such as project/problem-based learning that have clearer relationships to sustainability field competency development.

- Internships/apprenticeships can be highly effective learning devices, depending on the nature of the work performed or training received. These experiences can incorporate active learning, project/problem-based learning, integrative learning, research-based learning, reflexive learning, collaborative learning, and other effective pedagogies. The BASS program should continue to offer students opportunities to complete internships. However, due to the time-intensive nature of faculty oversight for multiple, distinct student internships with diverse organizations, and because many sustainability competencies related to project management may be taught more efficiently through project-based classes, an internship experience should not become a core requirement for the BASS degree. If internships continue to grow in popularity, BASS faculty members may need to seek additional resources to assist in administering them or place limits on the number of internships they supervise.

Discussion-based, writing-intensive, case study, experiential, and creative learning experiences should be built into the BASS core curriculum in existing courses and (if approved) in SUS 450 as implementation vehicles for the top nine pedagogies identified and discussed above. Doing so would create a richly diverse, experientially-oriented curriculum well suited to fostering sustainability competencies in program graduates. Learning communities and internships should also continue but should not supplant or slow work to initiate project-based learning through SUS 450 as a newly required course.

My findings with regard to sustainability pedagogies, together with the relationships drawn between these pedagogies and the BASS at CMC, provide insights that may be relevant to sustainability programs at other institutions.

\section{Conclusions}

My research indicates the following about the field of sustainability and its relationship to core competencies required to advance it:

- Sustainability is a transdisciplinary field that addresses complex issues and challenges by involving multiple disciplines and professions in dialog and practice-it requires transdisciplinary competency. 
- Its concepts and practices are based in studying, understanding, engaging with, and changing complex systems-it requires systems competency.

- Sustainability involves addressing interrelated issues and challenges through effectively communicating with and involving diverse stakeholders (people and organizations) - it requires interpersonal and communication competency.

- It is ultimately about changing the way people live in industrial societies through studying and critiquing assumptions and practices that drive unsustainable practices-it requires critical and normative competency.

- Sustainability moves beyond critique and understanding to create and implement strategies for personal, social, and organizational change-it requires creative and strategic competency.

The competencies needed for effective sustainability praxis are both broad and deep, and with social and environmental change proceeding at an increasingly rapid pace, it can be difficult for educators to determine where to focus their program development and teaching efforts. My findings in the areas of both competencies and pedagogies for effective sustainability education imply the benefits of fully integrative, active, collaborative, and applied approaches to sustainability-oriented curriculum development and teaching-approaches that can directly involve students in learning and practicing transdisciplinary engagement in service to sustainability.

Through this research, I have also learned that CMC's Sustainability Studies program prepares graduates well for engagement and further study in the field. Relative to the sustainability competencies articulated here, the BASS is timely and well founded, though continued improvement is possible and recommended, especially in the areas of teaching effective communication and engaging students in projects. My research serves as a stepping stone for the BASS faculty to further develop the Sustainability Studies program at CMC in ways that enhance student mastery of sustainability competencies. The competency framework and pedagogical recommendations offered here can also serve as roadmaps for sustainability educators more broadly to prepare students to address the pressing challenges to sustainability evident in communities, nations, and the world.

Funding: This research received no external funding.

Acknowledgments: The author would like to acknowledge the sabbatical leave support of Colorado Mountain College that allowed her the time to complete this research and the involvement of her Sustainability Studies faculty colleagues in continual program improvement. She would also especially like to acknowledge the continual support of her dear husband, professor, and scholar Dennis W. Lum, who assisted her with idea development and articulation for so much of her scholarly work throughout her career to date and who passed away during the writing of this article. His encouragement, love, and insights will be sorely missed.

Conflicts of Interest: The author declares no conflict of interest.

\section{Appendix A. Priority Rankings for Literature Review}

Appendix A.1. Audience

Tier 1: General, well-supported material targeted toward a related audience or the general public

Tier 2: General, well-supported material targeted toward specific audience

Tier 3: Extensive and specific coverage targeted toward a related audience or the general public

Tier 4: Extensive and specific coverage with general applicability to specific audience

Tier 5: Extensive and specific coverage with strong applicability targeted specifically toward audience

\section{Appendix A.2. Methodology}

Tier 1: Journalistic, secondary source publication that does not adhere to scholarly conventions

Tier 2: Publication for a general audience that adheres to scholarly conventions, is well argued, and presents a wide-ranging synthesis of broad themes in the literature and/or in practice 
Tier 3: Scholarly or industry publication: expert reflection on practice or opinion piece based on extensive experience

Tier 4: Scholarly or industry publication: well-argued and supported theory or synthesis piece

Tier 5: Scholarly or industry publication: well argued and supported with original empirical research

\section{Appendix A.3. Pedagogy}

Tier 1: Generalized, minimal recommendations for pedagogy

Tier 2: Section of the work devoted specifically to pedagogy, does not include specific examples

Tier 3: Section of the work devoted specifically to pedagogy, includes specific examples

Tier 4: Extensive and overarching focus on pedagogy that is general in nature

Tier 5: Extensive and overarching focus on pedagogy that includes specific examples

\section{Appendix A.4. Competencies}

Tier 1: Generalized, minimal, or implied discussion of competencies

Tier 2: Section of the work devoted specifically to competencies, does not include specific descriptions/examples

Tier 3: Section of the work devoted specifically to competencies, includes specific descriptions/examples Tier 4: Extensive and overarching focus on competencies that is general in nature

Tier 5: Extensive and overarching focus on competencies that includes specific descriptions/examples

\section{Appendix B. Core Curriculum Course Descriptions and Learning Outcomes for Colorado Mountain College's Bachelor of Arts Program in Sustainability Studies}

\section{Appendix B.1. BASS Required Course Descriptions and Outcomes}

The following course descriptions and learning outcomes have been developed over several years with the collaborative input of multiple CMC faculty members. Course descriptions are also available via the BASS program website, and course learning outcomes are included in all course syllabi distributed to enrolled students and available to the public.

\section{Appendix B.2. SUS 300, Foundations of Sustainability}

Introduces sustainability as a concept and practice. Explores the history and evolution of sustainability and examines key social, environmental, economic, and other factors that point to the need for sustainability-oriented social change. Provides a foundation to begin to evaluate sustainability in its social and historical context as a critical, paradigm shifting process. Introduces issues related to overshoot and potential collapse of modern industrial societies such as pressing challenges to water, food, and energy systems. Also addresses innovative perspectives and practices related to increasing socio-ecological resilience such as ecological design, biomimicry, adaptive management, permaculture, sustainable business, and transition initiatives.

1. Explain the history of sustainability as a concept, practice, and movement.

2. Evaluate diverse conceptual and practical approaches to sustainability.

3. Explain sustainability as a critical, paradigm shifting process.

4. Explain core principles of sustainability as they apply to a variety of settings and scales.

5. Identify multiple tools and strategies to promote sustainability initiatives.

6. WAC Outcome: Demonstrate abilities to formulate effective arguments through interpreting texts, organizing arguments, and supporting claims through use of evidence. 


\section{Appendix B.3. SUS 301, Systems Thinking and Sustainability}

Explores solutions to sustainability issues that often seem daunting because they are usually approached in a conventional problem solving methodology (reductionism, analysis of the individual parts). Systems thinking is an interdisciplinary approach to problem solving that emphasizes the interactions and connectedness of the different components and how they feedback and affect each other. In this class, students will learn how systems work, understand systems thinking, and apply different systems models to sustainability problems.

1. Differentiate between analyses and systems thinking problems.

2. Understand fundamental systems concepts and terminology.

3. Understand basic systems dynamics.

4. Understand basic systems thinking models.

5. Apply systems thinking to sustainability problems.

\section{Appendix B.4. SUS 310, Ecology and Sustainability}

Explores the inter-relationships between organisms and their past, present, and future environments. Relationships include the physiological responses of individuals, the structure of populations, the interactions among species, the organization of biological communities, and the processing of energy and matter in ecosystems. Course addresses the biotic (living) and abiotic (non-living) factors that influence the distribution, abundance, and diversity of life on Earth. Ecosystem function, health, and sustainability will be explored in the context of global change and human impacts on natural systems. Includes laboratory and field experiences.

1. Identify the Earth's biomes, their distribution, and ecological function.

2. Explain the process of evolution through natural selection, adaptation, and niche specialization.

3. Demonstrate an understanding of population growth, dispersal, connectivity, and extinction.

4. Explore exploitative interactions between species, including predation, herbivory, competition, parasitism, and disease.

5. Acquire familiarity with concepts and theories important to trophic ecology and energy transfer.

6. Demonstrate an understanding of the ecology of disturbance, succession, stability and resilience.

7. Acquire familiarity with concepts and theories important to social ecological systems and their sustainability.

8. Apply ecological knowledge to current and future challenges in global change ecology.

9. Demonstrate a basic understanding of ecological modeling and basic statistical tests/analyses related to the field.

\section{Appendix B.5. SUS 311, Integrated Sustainability Science}

Draws upon and integrates knowledge from biological, physical, and social sciences to foster an interdisciplinary understanding of sustainability. Recognizes the relevance of scientific knowledge to sustainability as a process of social change and technological innovation. The course focuses on how diverse sciences inform sustainability initiatives, including non-western/indigenous science. Explores applied sustainability in inter- and transdisciplinary areas such as sustainability science research, urban/community planning, agro- and/or industrial ecology, and ecodesign.

1. Integrate an understanding of sustainability derived from multiple scientific disciplines.

2. Evaluate quantitative and qualitative evidence used to support approaches to understanding and addressing challenges to sustainability.

3. Formulate responses to climate change and other sustainability challenges that draw upon and integrate knowledge from multiple science disciplines.

4. Design approaches to research that further understanding and/or implementation of sustainability. 
Appendix B.6. SUS 320, Literature for Change

Interdisciplinary in nature, this course examines landmark texts that have shaped and are shaping sustainability thought and action. Texts are interpreted rhetorically within their historical, cultural, and political contexts in order to highlight their effects on policy, on conceptions of human relationships with the environment, and on social equity/justice. Texts are drawn from multiple genres that may include fiction, poetry, journalism, policy, nonfiction, scientific communication, public discourse, blogs, multimedia works, and film. Students analyze how and why particular texts have been/are highly influential within the growing body of sustainability thought. Voices emanating from diverse cultures globally are included.

1. Identify and analyze various literary forms, modes, or genres of works studied.

2. Describe social, cultural, and historical contexts within which texts emerge.

3. Recognize themes in sustainability literature.

4. Identify effective rhetorical strategies through which authors express the need for sustainability-oriented social change.

5. Describe effects texts have on sustainability thought.

6. Interpret the cultural relevance of texts.

7. Articulate the personal relevance and value of texts with regard to sustainability thinking and action.

8. WAC Outcome: In writing, develop an intertextual analysis that reveals how two or more texts function as contributions to one or more broad conversation about the meaning, importance, and/or function of sustainability.

\section{Appendix B.7. SUS 321, Leadership, Ethics, and Social Responsibility}

Examines frameworks for effective and ethically grounded leadership and collective action through exploring contemporary social, humanitarian, business, economic, and/or sustainability issues. Through studying and interpreting interdisciplinary and cross-cultural texts, students examine questions of ethics, meaning, purpose, power, and value. Readings are relevant to students from diverse majors. Students develop their leadership and collaborative potentials through engaging in applied research and/or project-based learning. Students also draw on inter- and transdisciplinary course content to articulate conceptual and practical frameworks for themselves as emerging leaders in a complex world.

1. Develop a conceptual and ethical framework for discussing personal and social responsibility in a complex world.

2. Demonstrate understanding of diverse perspectives articulated in multicultural readings on ethics and leadership.

3. Identify and analyze real-world ethical problems and identify those communities and groups most affected.

4. Exhibit the ability to interact and work with people of distinct backgrounds toward a common goal.

5. Synthesize information from diverse disciplines and perspectives to articulate a framework for ethically grounded leadership.

6. Explain multiple perspectives on leadership and their roles in sustainability-oriented action.

7. Demonstrate values and skills of active citizenship through engaging in applied research and/or project-based learning.

\section{Appendix B.8. SUS 330, Sustainable Economics}

Presents an interdisciplinary approach to economics that includes concepts from ecology, physical science, and behavioral economics. Places traditional economic concepts within a foundation of 
sustainability by stressing the essential interconnections among the environment, economics, and social equity. Explores the limits of neoclassical economics to explain and predict economic phenomena and the failure of the mainstream economic approach to situate these phenomena sufficiently within biophysical and social equity contexts. Students develop systemic and contextual understanding of economic theory and economic phenomena. This understanding forms a basis for seeking potential solutions to problems of unsustainability through a transdisciplinary approach to economic change.

1. Evaluate the limits of approaching complex societal problems through a narrow (reductionist) disciplinary approach.

2. Demonstrate an in-depth understanding of major critiques of neoclassical economics.

3. Demonstrate an in-depth understanding of at least one major, sustainability-oriented theoretical/practical alternative to neoclassical economics.

4. Demonstrate a firm understanding of the first and second laws of thermodynamics and the limitations they impose on real-world environmental, economic, and social equity problems.

5. Explain economic relationships among the natural world, business, and social institutions.

6. Explain relationships between sustainability and economic efficiency.

7. Understand the value of ecosystem services and how these services can be evaluated using sustainable economic analysis and tools.

8. Acquire familiarity with concepts and theories important to sustainable economics such as: ecosystem resources, market allocation, stock-flow and fund-service resources, monetary theory, public goods, market failures, externalities, throughput, and growth versus development.

9. Demonstrate an understanding of approaches to solving resource problems in the abiotic and biotic realm using sustainable economic analysis and management tools.

\section{Appendix B.9. SUS 331, Cultural and Place Based Equity}

Focuses on how issues of culture and place relate to sustainability. Students will learn how sustainability involves relationships between people and places. A variety of global cultures, including those of nonwestern and/or indigenous societies, are considered in order to envision diverse perspectives on sustainability. Students will explore and discuss sustainability in terms of environmental health, justice, equity, and security. The course invites critical thinking and reflection and also challenges students to analyze the situations in which they live and participate.

1. Develop a broad awareness of cultural perspectives related to sustainability.

2. Understand places as contexts for considering issues of power and equity in sustainability.

3. Explain the emergence and current initiatives of the environmental justice movement.

4. Examine personal perspectives on sustainability in light of other cultural perspectives and ways of knowing.

5. Examine conflict, war, and diaspora in relationship to environmental scarcity, security, and sustainability.

6. WAC Outcome 1: Formulate a research question about sustainability related to the intersections of culture and place.

7. WAC Outcome 2: Conduct academic research relevant to the question posed.

8. WAC Outcome 3: Employ logical organization and argumentation to address the research question posed.

9. WAC Outcome 4: Formulate and support claims in an academic essay.

\section{Appendix B.10. SUS 410, Conservation Biology}

Explores the science and practice of biological conservation with the goal of preserving Earth's biodiversity. Students will examine the causes of reduction in biodiversity from local to global scales and investigate practical approaches to prevent the extinction of species, maintain genetic diversity 
within species, and protect and restore biological communities and their associated ecosystem functions. Conservation biology is an inter- and transdisciplinary field that applies scientific knowledge to the process of conservation through strategies such as habitat restoration, wildlife conservation, adaptive management, and social/cultural change. This course also addresses diverse cultural approaches to conservation, including community based natural resource management and nonwestern and/or indigenous approaches associated with traditional ecological knowledge. Includes laboratory and field experiences.

1. Explain central concepts and theories of conservation biology.

2. Identify patterns in biological diversity, biogeography, and biodiversity distribution.

3. Identify major causes of biodiversity loss, species isolation, invasion, disease, and extinction.

4. Describe strategies for conservation, protection, restoration, and sustainable management.

5. Apply conservation knowledge through engaging in conservation practices, communicating knowledge, or other means.

6. Identify and prioritize policies/actions to foster biodiversity, ecological resilience, and ecosystem health.

\section{Appendix B.11. SUS 416, Careers and Professional Skills in Sustainability}

Helps answer the question, "What are you going to do with a degree in Sustainability Studies?" by preparing students for initial employment, career advancement, or graduate education in the field of sustainability. Specifically, students will learn job skills-including interviewing, networking, resume and cover letter writing, and searching for employment locally, regionally, nationally, and abroad-for myriad sustainability career paths. Each student chooses a desirable post-graduation career or education pathway and will go through the process of applying for jobs and exploring graduate school programs. As a vehicle for highlighting professional abilities in the field, students develop and present professional sustainability portfolios—which culminate past coursework-with a particular employer or graduate program in mind. This course must be taken concurrently with SUS 489.

1. Explore and articulate professional career paths and post-graduate educational goals beyond completion of the program.

2. Identify jobs and graduate degrees of interest in the field, prepare application materials, and apply.

3. Demonstrate strategies for effective interviewing, and the successful communication of personal and professional statements as they pertain to sustainability.

4. Create a portfolio that is representative of one's scholarly/professional/voluntary/civic work relevant to sustainability.

5. Peer-review, revise, and refine professional materials for post-graduate use.

6. WAC Outcome 1: Produce high quality professional materials in support of job applications in the sustainability field.

7. WAC Outcome 2: Create a professional portfolio that represents one's scholarly/professional/ voluntary/civic work in the field and is addressed to a specific audience.

\section{Appendix B.12. SUS 420, Writing for Sustainability}

Engages students in analyzing diverse forms of sustainability-oriented writing aimed at communicating effectively to a broad range of audiences. Forms of writing addressed may include feature articles, narratives, editorials, essays, blogs, policies, creative nonfiction, and signs/public information used in displays; oral traditions may also be explored. Students also engage in reading and authoring communications designed to secure support for sustainability initiatives. Examples include letters and petitions as well as grant, research, and project proposals. To learn effective writing strategies, students analyze writing modes, techniques, and devices. They then apply these elements in their own writing within a classroom peer review setting. 
1. Develop a critical understanding of published models of sustainability writing.

2. Analyze writing conventions for particular genres (i.e. what it means to write for audiences of feature magazine articles, essays, newspaper articles, etc.).

3. Constructively critique others' work. Provide in-depth and effective feedback with particular attention to the audience for the given work.

4. Understand how socio-political literature and environmental literature can be effective tools of the writer-activist.

5. WAC Outcome 1: Structure and compose writings tailored to audience expectations within a defined genre.

6. WAC Outcome 2: Use a variety of sources for research and writing.

7. WAC Outcome 3: Demonstrate correct mechanics of writing including syntax, grammar, punctuation, and spelling.

8. WAC Outcome 4: Apply effective revision strategies.

\section{Appendix B.13. SUS 421, Fostering Sustainable Behaviors}

This course explores the roles of individuals, groups, and entire societies in fostering/inhibiting sustainable behaviors. Students study how changing individual worldviews and behaviors as well as altering pervasive social constructs are at the heart of sustainability work, and they explore diverse pathways for encouraging and implementing sustainability-oriented social change. Students explore how a variety of perspectives from fields such as environmental sociology, ecological and conservation psychology, political ecology, and social ecology can contribute to formulating appropriate personal and social responses to the sustainability crisis and to fostering sustainability-oriented social change.

1. Examine the human dimensions of environmental problems.

2. Think critically about the roles of individual and group behaviors in fostering local and global sustainability.

3. Understand a variety of disciplinary/interdisciplinary perspectives related to sustainability challenges and their potential solutions.

4. Formulate educational approaches to fostering sustainability.

5. Make connections among individual, local, and global sustainability initiatives.

6. Understand the roles of communication and social processes in creating sustainable solutions.

7. Develop strategies for implementing sustainability initiatives and/or projects.

\section{Appendix B.14. SUS 430, Sustainable Business}

Uses the triple bottom line sustainability framework to introduce students to in-depth principles and practices of sustainable business. Students learn how sustainable businesses can serve as vehicles to pursue integrated approaches to restoring the environment, ensuring long-term economic profitability, and fostering social equity. In order to recognize and analyze the widespread potential for and challenges to application of sustainable business principles, students explore and evaluate contemporary sustainable business initiatives and successes.

1. Develop efficacy with regard to business culture and communication.

2. Explain key assumptions and developments in the prevailing economic system and their effects on the environment, profitability, and social equity and justice.

3. Define basic principles of sustainability in the business realm.

4. Articulate rationales for a triple bottom line approach to sustainable business.

5. Analyze sustainable business problems and successes, locally and internationally.

6. Recommend sustainability best practices in the business realm by applying systems thinking to the sustainable business situation.

7. Recognize how sustainable businesses can be resilient in a changing world. 


\section{Appendix B.15. SUS 431, Social Entrepreneurship}

Provides students an in-depth introduction to the concepts and practices of social entrepreneurship: the innovative use of entrepreneurial and market principles and practices to address environmental, economic, and social equity problems. Students analyze and evaluate social entrepreneurial initiatives in order to learn how to enhance social and natural capital using approaches drawn from social business, impact investment, microfinance, and eco-preneurial organizational management, among others. Exposes students to social innovation across diverse geographies and cultural settings, with a focus on leading exemplars in the Global South.

1. Recognize the urgency, scale, and pervasiveness of sustainability challenges.

2. Understand theories of social entrepreneurship.

3. Articulate rationales for social entrepreneurship as an approach to implementing sustainability.

4. Identify social entrepreneurial opportunities in diverse community settings.

5. Formulate approaches to social entrepreneurship.

6. Recognize defining qualities of social entrepreneurs and social entrepreneurial organizations.

7. Examine key challenges of social entrepreneurial organizations and how to address these challenges.

8. Describe tools for measuring the effectiveness of social entrepreneurial organizations.

\section{Appendix B.16. SUS 489, Sustainability Capstone}

Provides an opportunity to reflect upon, refine, and synthesize learning over time within the major. Students complete an undergraduate thesis project for which one or more methodological approach is chosen, articulated, and applied. Students learn to effectively apply research ethics, with particular focus on ethical treatment of human and non-human subjects. Through a balance of theory and practice, students weave together interdisciplinary thought, problem-solving, and appropriate research methodologies for their research endeavor. Students share their broad mastery of learning across the curriculum through sharing research findings with a broad audience. Should be taken concurrently with SUS 416.

1. Comprehend and apply appropriate research methodologies in a chosen research endeavor.

2. Constructively critique the scholarly work of peers as part of the process of research project development.

3. Share scholarly research work with a broad audience.

4. Synthesize breadth and depth of inter- and transdisciplinary learning.

5. Reflect upon acquired knowledge and its meaning to one's life and work.

6. Articulate an understanding of sustainability as a concept and practice.

7. WAC Outcome 1: Conduct high quality scholarly research to support the undergraduate thesis.

8. WAC Outcome 2: Effectively convey research findings and conclusions in a scholarly paper through use of writing and reference conventions appropriate to the field.

\section{Appendix C. Course Rationale and Proposed Description and Learning Outcomes for Sustainability Assessment and Reporting (SUS 450)}

Course Rationale: This course is designed to develop interpersonal, project management, and sustainability assessment competencies for the sustainability field that were identified as central to the success of sustainability practitioners through research conducted by Tina Evans. Competencies for this course are important for graduate success and are not well developed in other required BASS or general education courses.

Course Description: Covers interpersonal and strategic, group and individual processes of conducting sustainability assessments using established frameworks and best practices. Assessments 
performed may serve businesses, nonprofits, educational institutions, government agencies, or other entities. Assessments performed utilize quantitative and qualitative methods to measure performance on sustainability indicators and to make recommendations for changes to policies, processes, and/or practices. Relevant policy frameworks are addressed through the assessment process.

Learning Outcomes:

1. Assess sustainability of an organization/process by using appropriate quantitative and qualitative measures and applying relevant frameworks and best practices.

2. Communicate clearly, transparently, inclusively, and in a timely manner with project team members and stakeholders to facilitate the progress of the sustainability assessment process.

3. Create one or more systems map relevant to the assessment project.

4. Conduct research to support the sustainability assessment.

5. Facilitate the progress of the project team by completing individually assigned work in a thorough, high quality, and timely manner.

6. Demonstrate leadership and participation skills that foster project team success.

7. Communicate assessment findings to stakeholders using appropriate written, visual, presentation, and/or other means.

8. Design approaches to improve the sustainability of the organization/processes assessed.

9. WAC outcome: write an executive summary of the assessment report.

Topical Outline:

1. Sustainability assessment frameworks and best practices.

2. Project management best practices.

3. Effective and inclusive team participation and leadership.

4. Accountability for project participants and leaders.

5. Communication best practices for project management and stakeholder engagement.

6. Meeting and workflow facilitation.

7. Systems mapping for sustainability assessments.

8. Relevant policy frameworks and laws.

9. Quantitative and qualitative assessment methods and tools.

10. Research best practices for sustainability assessments.

11. Communicating assessment results in writing, visually, and through presentations.

12. Designing approaches to improve sustainability of an organization/process.

\section{Appendix D. Full Resource List for this Study}

Allen, K. Critical internal shifts for sustainable leadership. In Innovation in Environmental Leadership; Redekop, B.W., Gallagher, D.R., Satterwhite, R., Eds.; Routledge: New York, NY, USA, 2018; pp. 213-224. Andrews, S. We don't conquer mountains, we understand them: Embedding indigenous education in Australian outdoor education. In Innovation in Environmental Leadership; Redekop, B.W., Gallagher, D.R., Satterwhite, R., Eds.; Routledge: New York, NY, USA, 2018; pp. 198-212.

Aoun, J.E. Robot-proof: Higher Education in the Age of Artificial Intelligence; The MIT Press: Cambridge, MA, USA, 2017.

Association for the Advancement of Sustainability in Higher Education (AASHE). STARS Technical Manual, version 2.1, administrative update two; AASHE: Philadelphia, PA, USA, 2017.

Bendell, J.; Little, R.; Sutherland, N. The seven unsustainabilities of mainstream leadership. In Innovation in Environmental Leadership; Redekop, B.W., Gallagher, D.R., Satterwhite, R., Eds.; Routledge: New York, NY, USA, 2018; pp. 13-31. 
Bignell, B. Beauty as a way of knowing: The redemption of knowing through the experience of beauty. In Handbook of Sustainability Literacy: Skills for a Changing World; Stibbe, A., Ed.; Green Books: Totnes, Devon, United Kingdom, 2011; pp. 191-195.

Blewitt, J. New media literacy: Communication skills for sustainability. In Handbook of Sustainability Literacy: Skills for a Changing World; Stibbe, A., Ed.; Green Books: Totnes, Devon, United Kingdom, 2011; pp. 111-116.

Blincoe, K. Re-educating the person. In Handbook of Sustainability Literacy: Skills for a Changing World; Stibbe, A., Ed.; Green Books: Totnes, Devon, United Kingdom, 2011; pp. 204-208.

Bond, G.D. Buddhism at Work: Community Development, Social Empowerment, and the Sarvodaya Movement; Kumarian: Bloomfield, CT, USA, 2004.

Brundiers, K.; Wiek, A. Beyond interpersonal competence: Teaching and learning professional skills in sustainability. Educ. Sci. 2017, 7, 39.

Bughin, J.; Hazan, E.; Lund, S.; Dahlstrom, P.; Wiesinger, A.; Subramaniam, A. Skill Shift: Automation and the Future of the Workforce. McKinsey Global Institute, 2018.

Cajete, G. Native Science: Natural Laws of Interdependence. Clear Light: Santa Fe, NM, USA, 2000.

Carteron, J.C.; Rowe, D.; Ng, K. The Sustainability Literacy Test: Implementation Strategies for Campuses. AASHE webinar. Available online: https:/www.youtube.com/watch?v=C2UdfXZ8gLM (accessed on 4 July 2019).

Clavin, A. Community gardening: Skills for building community and working within environmental limits. In Handbook of Sustainability Literacy: Skills for a Changing World; Stibbe, A., Ed.; Green Books: Totnes, Devon, United Kingdom, 2011; pp. 70-76.

Cletzer, D.A.; Kaufman, E.K. Eco-leadership, complexity science, and 21st-Century empirical analysis. In Innovation in Environmental Leadership; Redekop, B.W., Gallagher, D.R., Satterwhite, R., Eds.; Routledge: New York, NY, USA, 2018; pp. 80-96.

Clifford, M. Appropriate technology and appropriate design: The ability to design systems, technology and equipment in an appropriate way. In Handbook of Sustainability Literacy: Skills for a Changing World; Stibbe, A., Ed.; Green Books: Totnes, Devon, United Kingdom, 2011; pp.144-149.

Collins, R. The end of middle-class work: No more escapes. In Does Capitalism have a Future? Wallerstein I.M., Ed.; Oxford University Press: Oxford, United Kingdom, 2013, pp. 37-69.

Crawford, P.; Lang, S.; Fink, W.; Dalton, R.; Fielitz, L. Comparative Analysis of Soft Skills: What is Important for New Graduates? Association of Public and Land-grant Universities and University-industry Consortium, 2011.

Crow, M. Designing the New American University. Johns Hopkins University Press: Baltimore, MD, USA, 2015.

Curtiss, A. (2018). Holistic Learning, Education for Sustainable Development, and the Hidden Curriculum of Higher Learning in Sri Lanka: A Case Study of Sarvodaya's Institute of Higher Learning. Master's Thesis, Brandeis University, Waltham, MA, USA, 2018.

Danvers, J. Being-in-the-world: The ability to think about the self in interconnection and interdependence with the surrounding world. In Handbook of Sustainability Literacy: Skills for a Changing World; Stibbe, A., Ed.; Green Books: Totnes, Devon, United Kingdom, 2011; pp. 185-190.

Davidson, C.N. The New Education: How to Revolutionize the University to Prepare Students for a World in Flux. Basic Books: New York, NY, USA, 2017.

Davies, K. A learning society. In Handbook of Sustainability Literacy: Skills for a Changing World; Stibbe, A., Ed.; Green Books: Totnes, Devon, United Kingdom, 2011; pp. 215-220.

Dworkin, S. (2018, Oct. 10), ISSP sustainability professional credentials [Webinar]. Retrieved from https://vimeo.com/262471338

Evans. T. Green community based learning. In Green Education: An A-Z Guide; Newman, J., Ed.; SAGE Reference Series on Green Society; Robbins, P., Series Ed.; Sage: Los Angeles, CA, USA, 2011. 
Evans, T.L. Critical social theory and sustainability education at the college level: Why it's critical to be critical. J. Sustain. Educ. 2010, 1, Available online: http://www.jsedimensions.org/wordpress/wpcontent/uploads/2010/05/TinaEvans-JSE-Vol-1-May-2010.pdf (accessed on 28 Sept. 2019).

Evans, T.L. (2010, April). Purposes of multidisciplinary, interdisciplinary, and transdisciplinary programs. Available online: https://www.academia.edu/2315140/Purposes_of_Multidisciplinary_ Interdisciplinary_and_Transdisciplinary_Programs_April_2010 (accessed 4 July 2019).

Evans, T.L. Occupy Education: Living and Learning Sustainability. Peter Lang: New York, NY, USA, 2012. Evans, T.L. (2015). Transdisciplinary collaborations for sustainability education: Institutional and intragroup challenges and opportunities. Policy Futures Educ 2015, 13(1), 70-96.

Evans, T.L. Finding heart: Generating and maintaining hope and agency through sustainability education. J Sustainability Educ 2015 10. Available online: http://www.jsedimensions.org/wordpress/wpcontent/uploads/2015/11/Evans-Heart-JSE-Nov-2015-Hope-Issue-PDF.pdf (accessed on 4 July 2019).

Evans, T.L. Sustainable leadership: Toward restoring the human and natural worlds. In Innovation in Environmental Leadership; Redekop, B.W., Gallagher, D.R., Satterwhite, R., Eds.; Routledge: New York, NY, USA, 2018; pp. 61-79.

Evans, T.L. Transdisciplinary engagement with enforced dependency: A platform for higher education to address crises in employment, sustainability, and democracy in technological society. In Education and Technological Unemployment; Peters, M.A., Jandric, P., Means, A.J., Eds.; Springer: Cham, Switzerland, 2019; pp. 61-77.

Fagan, G. Citizen engagement. In Handbook of Sustainability Literacy: Skills for a Changing World; Stibbe, A., Ed.; Green Books: Totnes, Devon, United Kingdom, 2011; pp. 199-203.

Feng, L. (2011). Effortless action: The ability to fulfil human needs effortlessly through working with nature. In Handbook of Sustainability Literacy: Skills for a Changing World; Stibbe, A., Ed.; Green Books: Totnes, Devon, United Kingdom, 2011; pp. 58-63.

Fisher, P.B. Developing whole-systems competency in higher education to meet emerging market demand and societal sustainability. Sustainability 2014, 7(1), 54-62.

Garrard, G. Ecocriticism: The ability to investigate cultural artefacts from an ecological perspective. In Handbook of Sustainability Literacy: Skills for a Changing World; Stibbe, A., Ed.; Green Books: Totnes, Devon, United Kingdom, 2011; pp. 19-24.

Glasser, H.; Hirsh, J. Toward the development of robust learning for sustainability core competencies. Sustainability 2016 9(3), 121-134.

Goldberg, M. Social conscience: The ability to reflect on deeply held opinions about social justice and sustainability. In Handbook of Sustainability Literacy: Skills for a Changing World; Stibbe, A., Ed.; Green Books: Totnes, Devon, United Kingdom, 2011; pp. 105-110.

Hall, C.A.S.; Klitgaard, K. Energy and the Wealth of Nations: An Introduction to Biophysical Economics, 2nd ed.; Springer: Cham, Switzerland: Springer, 2018.

Harding, S. Gaia awareness: Awareness of the animate qualities of the Earth. In Handbook of Sustainability Literacy: Skills for a Changing World; Stibbe, A., Ed.; Green Books: Totnes, Devon, United Kingdom, 2011; pp. 89-93.

Harper, G. Technology appraisal: The ability to evaluate technological innovations. In Handbook of Sustainability Literacy: Skills for a Changing World; Stibbe, A., Ed.; Green Books: Totnes, Devon, United Kingdom, 2011; pp. 150-155.

Hilser, S. Key Competencies to Action: Transdisciplinary Learning of Key Competencies for Sustainability. Master's thesis, Lund University Centre for Sustainability Studies, Lund, Sweden, 2016.

Holmgren, D. Permaculture: Principles and Pathways Beyond Sustainability. Holmgren Design Services: Hepburn, Victoria, Australia, 2011.

Hopkins, R. The Transition Companion: Making Your Community More Resilient in Uncertain Times. Chelsea Green: White River Junction, VT, USA, 2011. 
International Project Management Association (IMPA). Individual Competence Baseline for Project, Programme \& Portfolio Management. IMPA: Nijkerk, The Netherlands, 2015.

International Society of Sustainability Professionals (ISSP). Sustainability Practitioner Body of Knowledge. ISSP, 2013. Available online: http://www.cascadia.edu/discover/about/sustainability/documents/ Sustainability\%20Practicioner\%20Body\%20of\%20Knowledge.pdf (accessed on 18 July 2019).

International Society of Sustainability Professionals (ISSP). ISSP Sustainability Professional Certification: Candidate handbook. ISSP, 2018.

Kenrick, J. (2011). Commons thinking: The ability to envisage and enable a viable future through connected action. In Handbook of Sustainability Literacy: Skills for a Changing World; Stibbe, A., Ed.; Green Books: Totnes, Devon, United Kingdom, 2011; pp. 51-57.

Knight, B. A Behavioral Competency Model for Sustainability Leaders. Master's thesis, Cambridge Institute for Sustainability Leadership, Cambridge University, Cambridge, United Kingdom, 2016.

Koehn, P.H.; Uitto, J.I. (2014). Evaluating sustainability education: Lessons from international development experience. High Educ 2014, 67: 621-635.

Kohl, K. Becoming a Sustainable Organization: A Project and Portfolio Management Approach; CRC Press: Boca Raton, FL, USA, 2016.

Kumar, S. Grounded economic awareness: Economic awareness based on ecological and ethical values. In Handbook of Sustainability Literacy: Skills for a Changing World; Stibbe, A., Ed.; Green Books: Totnes, Devon, United Kingdom, 2011; pp. 30-36.

Lans, T.; Blok, V.; Wesselink, R. Learning apart and together: Towards an integrated competence framework for sustainable entrepreneurship in higher education. J Clean Prod 2014, 62: 37-47.

Lozano, R.; Merrill, M.Y.; Sammalisto, K.; Ceulemans, K.; Lozano, F.J. Connecting competences and pedagogical approaches for sustainable development in higher education: A literature review and framework proposal. Sustainability 2017, 9(1889): 1-15.

MacDonald, L.; Shriberg, M. Sustainability leadership in higher education: Alumni outcomes and impacts. J Environ Stud Sci 2016 6(2): 360-370.

Madsbjerg, C. Sensemaking: The Power of the Humanities in the Age of the Algorithm. Hachette Books: New York, NY, USA, 2017.

Maiteny, P. Finding meaning without consuming: The ability to experience meaning, purpose and satisfaction through non-material wealth. In Handbook of Sustainability Literacy: Skills for a Changing World; Stibbe, A., Ed.; Green Books: Totnes, Devon, United Kingdom, 2011; pp. 178-184.

Manyika, J.; Lund, S.; Chui, M.; Bughin, J.; Woetzel, J.; Batra, P.; Ko, R.; Sanghvi, S. Jobs Lost, Jobs Gained: Workforce Transitions in a Time of Automation. McKinsey Global Institute, 2017. Available online: https://www.mckinsey.com/ \{\}/media/mckinsey/featured\%20insights/Future\%20of\% 20Organizations/What $\% 20$ the $\% 20$ future $\% 20$ of $\% 20$ work $\% 20$ will $\% 20$ mean $\% 20$ for $\% 20$ jobs $\% 20$ skills $\%$ 20and\%20wages/MGI-Jobs-Lost-Jobs-Gained-Report-December-6-2017.ashx (Accessed 18 July 2019). Molderez, I.; Ceulemans, K. The power of art to foster systems thinking, one of the key competencies of education for sustainable development. J Clean Prod 2018, 186: 758-770.

Molderez, I.; Fonseca, E. The efficacy of real-world experiences and service learning for fostering competencies for sustainable development in higher education. J Clean Prod 2018, 172: 4397-4410.

Morris, D.; Martin, S. Complexity, systems thinking and practice: Skills and techniques for managing complex systems. In Handbook of Sustainability Literacy: Skills for a Changing World; Stibbe, A., Ed.; Green Books: Totnes, Devon, United Kingdom, 2011; pp. 156-164.

Moyer, B. (with McAllister, J.; Finley, J.L.; Soifer, S.). Doing Democracy: The MAP Model for Organizing Social Movements. New Society: Gabriola Island, BC, Canada, 2001.

Naish, J. (2011). Optimisation: The art of personal sufficiency. In Stibbe, A. (Ed.), Handbook of sustainability literacy: Skills for a changing world (pp. 25-29). Totnes, Devon, United Kingdom: Green Books. 
Newman, J. Values reflection and the Earth Charter: The ability to critique the values of an unsustainable society and consider alternatives. In Handbook of Sustainability Literacy: Skills for a Changing World; Stibbe, A., Ed.; Green Books: Totnes, Devon, United Kingdom, 2011; pp. 99-104.

O'Brien, W.; Sarkis, J. The potential of community-based sustainability projects for deep learning initiatives. J Clean Prod 2014, 62: 48-61.

de Oliveira, A.C.; Sokulski, C.C.; da Silva Batista, A.A.; de Francisco, A.C. Competencies for sustainability: A proposed method for the analysis of their interrelationships. Sustainable Prod Consump 2018, 14: 82-94.

Orr, D.W. The dangers of education. Encounter 2011, 24(11): 27-39.

Orr, D.W.; Cohen, A. Promoting partnerships for integrated, post-carbon development: Strategies at work in the Oberlin Project at Oberlin College. Plan High Educ J 2013, 41(3): 22-26.

Phillips, M. Emotional well-being: The ability to research and reflect on the roots of emotional well-being. In Handbook of Sustainability Literacy: Skills for a Changing World; Stibbe, A., Ed.; Green Books: Totnes, Devon, United Kingdom, 2011; pp. 171-177.

Phillips, A. Institutional transformation. In Handbook of Sustainability Literacy: Skills for a Changing World; Stibbe, A., Ed.; Green Books: Totnes, Devon, United Kingdom, 2011; pp. 209-214.

Ploum, L.; Blok, V.; Lans, T.; Omta, O. Toward a validated competence framework for sustainable entrepreneurship. Organ Environ 2018, 31: 113-132.

Polistina, K. Cultural literacy: Understanding and respect for the cultural aspects of sustainability. In Handbook of Sustainability Literacy: Skills for a Changing World; Stibbe, A., Ed.; Green Books: Totnes, Devon, United Kingdom, 2011; pp. 117-123.

Quilley, S. Transition skills: Skills for transition to a post-fossil-fuel age. In Handbook of Sustainability Literacy: Skills for a Changing World; Stibbe, A., Ed.; Green Books: Totnes, Devon, United Kingdom, 2011; pp. 43-50).

Rieckmann, M. Future-oriented higher education: Which key competencies should be fostered through university teaching and learning? Futures 2012, 44: 127-135.

Reickman, M. (2018). Learning to transform the world: Key competencies in ESD. In Issues and Trends in Education for Sustainable Development; Leicht, J., Byun, W.J., Eds.; United Nations Educational, Scientific and Cultural Organization (UNESCO), 2018; pp. 39-59.

Robinson, Z. Greening business: The ability to drive environmental and sustainability improvements in the workplace. In Handbook of Sustainability Literacy: Skills for a Changing World; Stibbe, A., Ed.; Green Books: Totnes, Devon, United Kingdom, 2011; pp. 130-136.

Sandri, O.J. Exploring the role and value of creativity in education for sustainability. Environ Educ Res 2013, 19: 765-778.

Sharma, S. Competing for a Sustainable World. Greenleaf: Sheffield, United Kingdom, 2014.

Sidiropoulos, E. The personal context of student learning for sustainability: Results of a multi-university research study. J Clean Prod 2018, 181: 537-554.

Silvius, G.; Schipper, R.; Planko, J.; van den Brink, J.; Köhler, A. Sustainability in Project Management. Gower: Burlington, VT, USA, 2012.

Singer-Brodowski, M. Students' competency development in the context of self-organized and project-oriented sustainability seminars. In Routledge Handbook of Higher Education for Sustainable Development; Barth, M., Michelsen, G., Rieckmann, M., Thomas, I., Eds.; Routledge: London, United Kingdom, 2016; pp. 411-420).

Smyth, T.S. Transdisciplinary pedagogy: A competency based approach for teachers and students to promote global sustainability. J Interdiscipl Stud Educ 2017, 5(2): 64-72.

Sterling, S. Sustainable Education: Re-visioning Learning and Change. Schumacher Briefings, no. 6. Green Books: Bristol, United Kingdom, 2004. 
Sterling, S. Ecological intelligence: Viewing the world relationally. In Handbook of Sustainability Literacy: Skills for a Changing World; Stibbe, A., Ed.; Green Books: Totnes, Devon, United Kingdom, 2011; pp. 77-83.

Stibbe, A. Advertising awareness: The ability to expose advertising discourses that undermine sustainability and resist them. In Handbook of Sustainability Literacy: Skills for a Changing World; Stibbe, A., Ed.; Green Books: Totnes, Devon, United Kingdom, 2011; pp. 37-42.

Strachan, G. Systems thinking: The ability to recognize and analyze the interconnections within and between systems. In Handbook of Sustainability Literacy: Skills for a Changing World; Stibbe, A., Ed.; Green Books: Totnes, Devon, United Kingdom, 2011; pp. 84-88.

Svanstrom, M.; Lozano-Garcia, F.J.; Rowe, D. Learning outcomes for sustainable development in higher education. Int J Sust Higher Ed 2008, 9(3): 339-351.

Tomkinson, B. Coping with complexity: The ability to manage complex sustainability problems. In Handbook of Sustainability Literacy: Skills for a Changing World; Stibbe, A., Ed.; Green Books: Totnes, Devon, United Kingdom, 2011; pp. 165-170.

Trencher, G.; Vincent, S.; Bahr, K.; Shogo, K.; Marham, K.; Yamanaka, Y. Evaluating core competencies development in sustainability and environmental master's programs: An empirical analysis. J Clean Prod 2018, 181: 829-841.

United Nations Department of Economic and Social Affairs. Youth Civic Engagement: World Youth Report. New York, NY, USA: United Nations, 2016.

United Nations Educational, Scientific and Cultural Organization (UNESCO). Shaping the Future We Want: UN Decade of Education for Sustainable Development (2005-2014), final report. UNESCO, 2014.

United Nations Educational, Scientific and Cultural Organization (UNESCO). Shaping the Future We Want: UN Decade of Education for Sustainable Development (2005-2014), final report, executive summary. UNESCO, 2014.

United Nations Educational, Scientific and Cultural Organization (UNESCO). Education for Sustainable Development Goals: Learning Objectives. UNESCO, 2017.

Wals, A.E.J. Sustainability in higher education in the context of the UN DESD: A review of learning and institutionalization processes. J Clean Prod 2014, 62: 8-15.

Watson, M. Materials awareness: The ability to expose the hidden impact of materials on sustainability. In Handbook of Sustainability Literacy: Skills for a Changing World; Stibbe, A., Ed.; Green Books: Totnes, Devon, United Kingdom, 2011; pp. 137-143.

Wayman, S. Futures thinking: The ability to envision scenarios of a more desirable future. In Handbook of Sustainability Literacy: Skills for a Changing World; Stibbe, A., Ed.; Green Books: Totnes, Devon, United Kingdom, 2011; pp. 94-98.

Western, S. (2018). The eco-leadership paradox. In Innovation in Environmental Leadership; Redekop, B.W., Gallagher, D.R., Satterwhite, R., Eds.; Routledge: New York, NY, USA, 2018; pp. 48-60.

Whitefield, P. Permaculture design: Designing our lives with nature as the model. In Handbook of Sustainability Literacy: Skills for a Changing World; Stibbe, A., Ed.; Green Books: Totnes, Devon, United Kingdom, 2011; pp. 64-69.

Whitmarsh, L.; O’Neill, S.; Seyfang, G.; Lorenzoni, I. Carbon capability: Understanding climate change and reducing carbon emissions. In Handbook of Sustainability Literacy: Skills for a Changing World; Stibbe, A., Ed.; Green Books: Totnes, Devon, United Kingdom, 2011; pp. 124-129.

Wiek, A.; Bernstein, M.J.; Foley, R.W.; Cohen, M.; Forrest, N.; Kuzdas, C.; Kay, B.; Keeler, L.W. Operationalizing competencies in higher education for sustainable development. In Routledge Handbook of Higher Education for Sustainable Development; Barth, M., Michelsen, G., Rieckmann, M., Thomas, I., Eds.; Routledge: London, United Kingdom, 2016; pp. 241-260.

Wiek, A.; Braden, K. Learning while transforming: Solution-oriented learning for urban sustainability in Phoenix, Arizona. Curr Opin Sust, 2015, 16: 29-36. 
Wiek, A.; Withycombe, L.; Redman, C.L. Key competencies in sustainability: A reference framework for academic program development. Sustain Sci 2011 6: 203-218.

Wiek, A.; Withycombe, L.; Redman, C.; Mills, S.B. Moving forward on competence in sustainability research and problem solving. Environment 2011, 53(2): 3-12.

Williard, M.; Weidmeyer, C.; Flint, R.W..; Weedon, J.S.; Woodward, R.; Feldman, I.; Edwards, M. The Sustainability Professional: 2010 Competency Survey Report. International Society of Sustainability Professionals, 2010. Available online: http://sustainabilityprofessionals.org/system/files/ISSP\% 20Special\%20Report_3.10_final_0.pdf (Accessed: 18 July 2019).

\section{Appendix E. Potential Future Enhancements for the BASS Program Curriculum at CMC}

Systems Competence:

Include/enhance:

- Anticipatory thinking and action.

- Self-reflexivity for systems observers/participants.

- Applied versions of systems thinking such as life-cycle analysis.

- Recognizing systems as human constructs that can be construed differently by different observers.

Critical and Normative Competence:

Include/enhance:

- Actual collaboration, negotiation of values/goals, and building common ground.

- Using enforced dependency as a lens for analysis and a springboard for action.

- More on moral/emotional work/understanding.

- More on indigenous worldviews/ethics/perspectives.

Creative and Strategic Competence:

Include/enhance:

- Focus on relevant policies, frameworks, and standards.

- Project management and assessment.

- Stakeholder engagement best practices.

- Partnership and coalition building.

- $\quad$ Taking initiative.

Interpersonal and Communication Competence

Include/enhance:

- Building knowledge and skills for activating sustainability on the ground within an organization or a community.

- Communication and collaboration skills other than writing.

Transdisciplinary Competence:

Include/enhance:

- Delineating and articulating the skills needed to do sustainability work on the ground.

- Application of transdisciplinary knowledge and skills in group and organizational settings.

- Engaging stakeholders beyond CMC. 


\section{References}

1. Wiek, A.; Withycombe, L.; Redman, C.L. Key competencies in sustainability: A reference framework for academic program development. Sustain. Sci. 2011, 6, 203-218. [CrossRef]

2. Wiek, A.; Bernstein, M.J.; Foley, R.W.; Cohen, M.; Forrest, N.; Kuzdas, C.; Kay, B.; Keeler, L.W. Operationalizing Competencies in Higher Education for Sustainable Development. In Routledge Handbook of Higher Education for Sustainable Development; Barth, M., Michelsen, G., Rieckmann, M., Thomas, I., Eds.; Routledge: London, UK, 2016; pp. 241-260.

3. Glasser, H. Toward the Development of Robust Learning for Sustainability Core Competencies. Sustain. J. Rec. 2016, 9, 121-134. [CrossRef]

4. Trencher, G.; Vincent, S.; Bahr, K.; Kudo, S.; Markham, K.; Yamanaka, Y. Evaluating core competencies development in sustainability and environmental master's programs: An empirical analysis. J. Clean. Prod. 2018, 181, 829-841. [CrossRef]

5. Hilser, S. Key Competencies to Action: Transdisciplinary Learning of Key Competencies for Sustainability. Master's Thesis, Lund University Centre for Sustainability Studies, Lund, Sweden, 2016.

6. Lozano, R.; Merrill, M.Y.; Sammalisto, K.; Ceulemans, K.; Lozano, F.J. Connecting Competences and Pedagogical Approaches for Sustainable Development in Higher Education: A Literature Review and Framework Proposal. Sustainability 2017, 9, 1889. [CrossRef]

7. Lans, T.; Blok, V.; Wesselink, R. Learning apart and together: Towards an integrated competence framework for sustainable entrepreneurship in higher education. J. Clean. Prod. 2014, 62, 37-47. [CrossRef]

8. Stibbe, A. (Ed.) Handbook of Sustainability Literacy: Skills for a Changing World; Green Books: Totnes, Devon, UK, 2011; pp. 37-42.

9. Knight, B. A Behavioral Competency Model for Sustainability Leaders. Master's Thesis, Cambridge Institute for Sustainability Leadership, Cambridge University, Cambridge, UK, 2016.

10. International Society of Sustainability Professionals (ISSP). Sustainability Practitioner Body of Knowledge. ISSP, 2013. Available online: http://www.cascadia.edu/discover/about/sustainability/documents/ Sustainability\%20Practicioner\%20Body\%20of\%20Knowledge.pdf (accessed on 18 July 2019).

11. Curtiss, A. Holistic Learning, Education for Sustainable Development, and the Hidden Curriculum of Higher Learning in Sri Lanka: A Case Study of Sarvodaya's Institute of Higher Learning. Master's Thesis, Brandeis University, Waltham, MA, USA, 2018.

12. Reickman, M. Learning to transform the world: Key competencies in ESD. In Issues and Trends in Education for Sustainable Development; Leicht, J., Byun, W.J., Eds.; United Nations Educational, Scientific and Cultural Organization (UNESCO): Paris, France, 2018; pp. 39-59.

13. United Nations Educational, Scientific and Cultural Organization (UNESCO). Education for Sustainable Development Goals: Learning Objectives; UNESCO: Paris, France, 2017.

14. Willard, M.; Wiedmeyer, C.; Flint, R.W.; Weedon, J.S.; Woodward, R.; Feldman, I.; Edwards, M. The sustainability professional: 2010 competency survey report. Environ. Qual. Manag. 2010, 20, 49-83. [CrossRef]

15. Association for the Advancement of Sustainability in Higher Education (AASHE). STARS Technical Manual, Version 2.1, Administrative Update Two; AASHE: Philadelphia, PA, USA, 2017.

16. Aoun, J.E. Robot-proof: Higher Education in the Age of Artificial Intelligence; The MIT Press: Cambridge, MA, USA, 2017.

17. Bughin, J.; Hazan, E.; Lund, S.; Dahlstrom, P.; Wiesinger, A.; Subramaniam, A. Skill Shift: Automation and the Future of the Workforce; McKinsey Global Institute: New York, NY, USA, 2018.

18. Madsbjerg, C. Sensemaking: The Power of the Humanities in the Age of the Algorithm; Hachette Books: New York, NY, USA, 2017.

19. Manyika, J.; Lund, S.; Chui, M.; Bughin, J.; Woetzel, J.; Batra, P.; Ko, R.; Sanghvi, S. Jobs Lost, Jobs Gained: Workforce Transitions in a Time of Automation. McKinsey Global Institute, 2017. Available online: https://www.mckinsey.com/ \{\}/media/mckinsey/featured\%20insights/Future\%20of\%20Organizations/ What $\% 20$ the $\% 20$ future $\% 20$ of $\% 20$ work $\% 20$ will\%20mean $\% 20$ for $\% 20$ jobs\%20skills $\% 20$ and $\% 20$ wages/MGIJobs-Lost-Jobs-Gained-Report-December-6-2017.ashx (accessed on 18 July 2019).

20. Collins, R. The end of middle-class work: No more escapes. In Does Capitalism Have a Future? Wallerstein, I.M., Ed.; Oxford University Press: Oxford, UK, 2013; pp. 37-69. 
21. Davidson, C.N. The New Education: How to Revolutionize the University to Prepare Students for a World in Flux; Basic Books: New York, NY, USA, 2017.

22. Crawford, P.; Lang, S.; Fink, W.; Dalton, R.; Fielitz, L. Comparative Analysis of Soft Skills: What is Important for New Graduates? Association of Public and Land-grant Universities and University-industry Consortium: Washington, DC, USA, 2011.

23. International Project Management Association (IMPA). Individual Competence Baseline for Project, Programme $\mathcal{E}$ Portfolio Management; IMPA: Nijkerk, The Netherlands, 2015.

24. Smyth, T.S. Transdisciplinary pedagogy: A competency based approach for teachers and students to promote global sustainability. J. Interdiscip. Stud. Educ. 2017, 5, 64-72.

25. Evans, T.L. Occupy Education: Living and Learning Sustainability; Peter Lang: New York, NY, USA, 2012.

26. Evans, T.L. Finding heart: Generating and maintaining hope and agency through sustainability education. J. Sustain. Educ. 2015, 10. Available online: http://www.jsedimensions.org/wordpress/wp-content/uploads/ 2015/11/Evans-Heart-JSE-Nov-2015-Hope-Issue-PDF.pdf (accessed on 4 July 2019).

27. Evans, T.L. Critical social theory and sustainability education at the college level: Why it's critical to be critical. J. Sustain. Educ. 2010, 1. Available online: http://www.jsedimensions.org/wordpress/wp-content/ uploads/2010/05/TinaEvans-JSE-Vol-1-May-2010.pdf (accessed on 28 September 2019).

28. Evans, T.L. Purposes of Multidisciplinary, Interdisciplinary, and Transdisciplinary Programs. 2010. Available online: https://www.academia.edu/2315140/Purposes_of_Multidisciplinary_Interdisciplinary_ and_Transdisciplinary_Programs_April_2010 (accessed on 4 July 2019).

29. Evans, T.L. Transdisciplinary collaborations for sustainability education: Institutional and intragroup challenges and opportunities. Policy Futur. Educ. 2015, 13, 70-96. [CrossRef]

30. Evans, T.L. Transdisciplinary Engagement with Enforced Dependency: A Platform for Higher Education to Address Crises in Employment, Sustainability, and Democracy in Technological Society; Springer Science and Business Media LLC: Cham, Switzerland, 2019; pp. 61-77.

(C) 2019 by the author. Licensee MDPI, Basel, Switzerland. This article is an open access article distributed under the terms and conditions of the Creative Commons Attribution (CC BY) license (http://creativecommons.org/licenses/by/4.0/). 